\title{
NOD1 contributes to mouse host defense against Helicobacter pylori via induction of type I IFN and activation of the ISGF3 signaling pathway
}

Tomohiro Watanabe, ${ }^{1,2}$ Naoki Asano, ${ }^{1}$ Stefan Fichtner-Feigl, ${ }^{1}$ Peter L. Gorelick, ${ }^{3}$ Yoshihisa Tsuji, ${ }^{2}$ Yuko Matsumoto, ${ }^{2}$ Tsutomu Chiba, ${ }^{2}$ Ivan J. Fuss, ${ }^{1}$ Atsushi Kitani, ${ }^{1}$ and Warren Strober ${ }^{1}$

\begin{abstract}
${ }^{1}$ Mucosal Immunity Section, Laboratory of Host Defenses, National Institute of Allergy and Infectious Diseases, NIH, Bethesda, Maryland, USA. 2Department of Gastroenterology and Hepatology, Kyoto University Graduate School of Medicine, Kyoto, Japan. ${ }^{3}$ Animal Health Diagnostic Laboratory, Laboratory Animal Sciences Program, National Cancer Institute — Frederick, Science Applications International Corporation, Frederick, Maryland, USA.
\end{abstract}

\begin{abstract}
Nucleotide-binding oligomerization domain 1 (NOD1) is an intracellular epithelial cell protein known to play a role in host defense at mucosal surfaces. Here we show that a ligand specific for NOD1, a peptide derived from peptidoglycan, initiates an unexpected signaling pathway in human epithelial cell lines that results in the production of type I IFN. Detailed analysis revealed the components of the signaling pathway. NOD1 binding to its ligand triggered activation of the serine-threonine kinase RICK, which was then able to bind TNF receptor-associated factor 3 (TRAF3). This in turn led to activation of TANK-binding kinase 1 (TBK1) and IKB kinase $\varepsilon(\mathrm{IKK} \varepsilon)$ and the subsequent activation of IFN regulatory factor 7 (IRF7). IRF7 induced IFN- $\beta$ production, which led to activation of a heterotrimeric transcription factor complex known as IFN-stimulated gene factor 3 (ISGF3) and the subsequent production of CXCL10 and additional type I IFN. In vivo studies showed that mice lacking the receptor for IFN- $\beta$ or subjected to gene silencing of the ISGF3 component Stat 1 exhibited decreased CXCL10 responses and increased susceptibility to Helicobacter pylori infection, phenotypes observed in NOD1-deficient mice. These studies thus establish that NOD1 can activate the ISGF3 signaling pathway that is usually associated with protection against viral infection to provide mice with robust type I IFN-mediated protection from $\mathrm{H}$. pylori and possibly other mucosal infections.
\end{abstract}

\section{Introduction}

Nucleotide-binding oligomerization domain 1 (NOD1) is a member of the NOD-like receptor family of proteins that can act as intracellular sensors of microbial components (1-3). Members of this protein family are structurally similar in that they are composed of a central NOD domain usually linked on its C-terminal side to a leucine-rich repeat domain that interacts with microbial components, and on its $\mathrm{N}$-terminal side to a caspase-recruitment domain (CARD) or PYRIN domain that can interact with downstream effector molecules (4). NOD1 and its sister molecule, NOD2, are CARD-containing molecules that fit this structural model and have leucine-rich repeats that recognize related (but distinct) muropeptide subunits of the bacterial cell wall component, peptidoglycan (PGN) $(1,5)$. NOD1 and NOD2 are mainly expressed in APCs and epithelial cells, which are exposed to microorganisms expressing PGN. Most gastrointestinal epithelial cell lines and, more importantly, primary epithelial cells, express NOD1 $(6,7)$, whereas NOD2 is present in specialized epithelial cells, known as Paneth cells, at the base of the intestinal crypt (8).

Recent studies of the function of NOD1 have revealed that activation by its stimulating muropeptide, $\gamma$-D-glutamyl-mesodiaminopimelic acid (iE-DAP), or certain synthetic derivatives of this peptide, KF1B (9), leads to the production of cytokines and chemokines by APCs and epithelial cells (10). Investigation of the signaling pathway utilized for such production has suggested that,

Conflict of interest: The authors have declared that no conflict of interest exists. Citation for this article: J Clin Invest. 2010;120(5):1645-1662. doi:10.1172/JCI39481. like NOD2, NOD1 effector function depends on the activation of RIP2 (RICK) and NF-KB $(5,9,11)$. It should be noted, however, that the involvement of NF- $\mathrm{BB}$ in this pathway is based mainly on signaling studies utilizing transfected cells in which NOD1 and/or an NF- $\mathrm{KB}$ reporter gene is over-expressed rather than on studies employing cells expressing endogenous NOD1 stimulated under physiologic conditions. Thus it is possible that signaling pathways not involving NF-кB activation play an important role in NOD1 induction of chemokines and cytokines.

Given the capacity of NOD1 to induce chemokines, such as IL-8 (CXCL8), it is likely to play an important role in host defense function at the interface of the organism with the gastrointestinal milieu $(7,9)$. This was in fact shown clearly in studies in which NOD1 activation was noted upon infection of epithelial cell monolayers with invasive E. coli (7). In addition, it has been reported that NOD1-deficient mice are more susceptible to gastric infection with Helicobacter pylori and that H. pylori activates NOD1 by gaining intracellular access via a type IV secretion system dependent on the cag pathogenicity island (12).

In the present study we focused on the signaling pathway that is initiated by NOD1 activation and show that it utilizes a pathway more commonly identified with cell signaling by viruses. This pathway involves first the generation of NOD1-activated RICK and then the binding of the latter to TRAF3, the key factor in determining the subsequent signaling events. This is then followed by the activation of TANK-binding kinase 1 (TBK1) and downstream components including IKKe and IFN regulatory factor 7 (IRF7), which is followed by the synthesis of type I IFN and signaling 

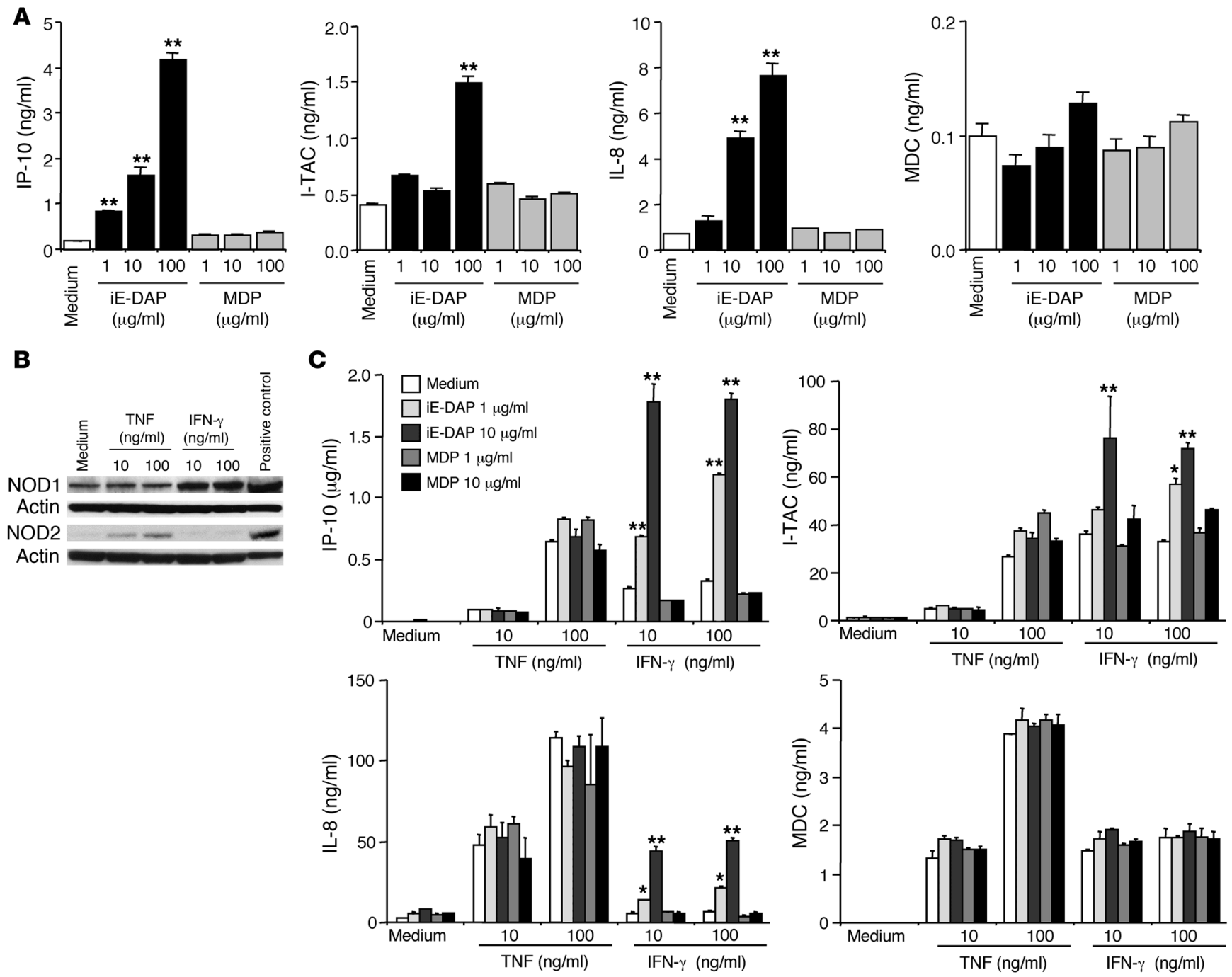

Figure 1

Production of chemokines by HT-29 cells stimulated with MDP or iE-DAP. (A) IP-10, I-TAC, IL-8, and MDC production by iE-DAP-stimulated HT-29 cells without IFN- $\gamma$ pretreatment. HT-29 cells $(106 / \mathrm{ml}$ in 6 -well plates) were stimulated with NOD1 ligand (iE-DAP; 1,10 , or $100 \mu \mathrm{g} / \mathrm{ml})$ or NOD2 ligand (MDP; 1,10 , or $100 \mu \mathrm{g} / \mathrm{ml}$ ) for 24 hours. Cultured supernatants were harvested and assayed. (B) NOD1 and NOD2 expression in HT-29 cells stimulated with TNF (10 or $100 \mathrm{ng} / \mathrm{ml}$ ) or IFN- $\gamma(10$ or $100 \mathrm{ng} / \mathrm{ml}$ ) for 24 hours. Whole cell lysates from HT-29 cells transfected with NOD1 and NOD2 cDNA were used for positive controls of NOD1 and NOD2 expression, respectively. (C) HT-29 cells (106/ml in 6-well plates) were cultured with IFN- $\gamma$ or TNF (10 or $100 \mathrm{ng} / \mathrm{ml}$ ) for 24 hours and then cultured with iE-DAP ( 1 or $10 \mu \mathrm{g} / \mathrm{ml}$ ) or MDP (1 or $10 \mu \mathrm{g} / \mathrm{ml}$ ) for another 24 hours. Cultured supernatants were harvested and assayed for the presence of IP-10, I-TAC, IL-8, and MDC by ELISA. Results shown are representative of 2 or 3 studies. Results are expressed as mean \pm SD. ${ }^{\star} P<0.05$; ${ }^{*} P<0.01$ compared with cells cultured with medium alone.

of the latter through IFN-stimulated gene factor 3 (ISGF3). The ISGF3 then transactivates chemokines and additional IRF7, the latter capable of amplifying type I IFN production and signaling. Thus, NOD1 contributes to host defense not only via upregulation of chemokine synthesis, but also through an unexpected ability to initiate type I IFN production.

\section{Results}

NOD1 induces epithelial cells to produce large amounts of proinflammatory chemokines. A diaminopimelic acid-containing molecule derived from PGN has been identified as a specific ligand for NOD1 (10). Thus, in initial experiments, we verified that the synthesized iE-DAP used in most of the studies is a specific activator of NOD1.
For this purpose, we transfected the HT-29 human colon epithelial cell line with a construct expressing the promoter for the gene encoding NF- $\mathrm{KB}$ linked to a luciferase reporter gene together with a construct expressing one of the TLRs or NOD-like receptors (13). The cells were then stimulated with ligands specific for the transfected recognition molecule as positive control or with iE-DAP. As shown in Supplemental Figure 1 (supplemental material available online with this article; doi:10.1172/JCI39481DS1),

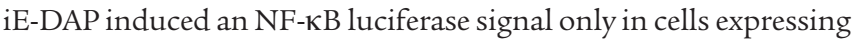
NOD1. It should be noted that NF-KB activation in this assay did not provide a reliable estimate of NOD1 signaling via NF- $\mathrm{KB}$ in physiologic cells, since the result could be heavily biased toward showing a NOD1 effect on NF-KB signaling due to the sensitivity 

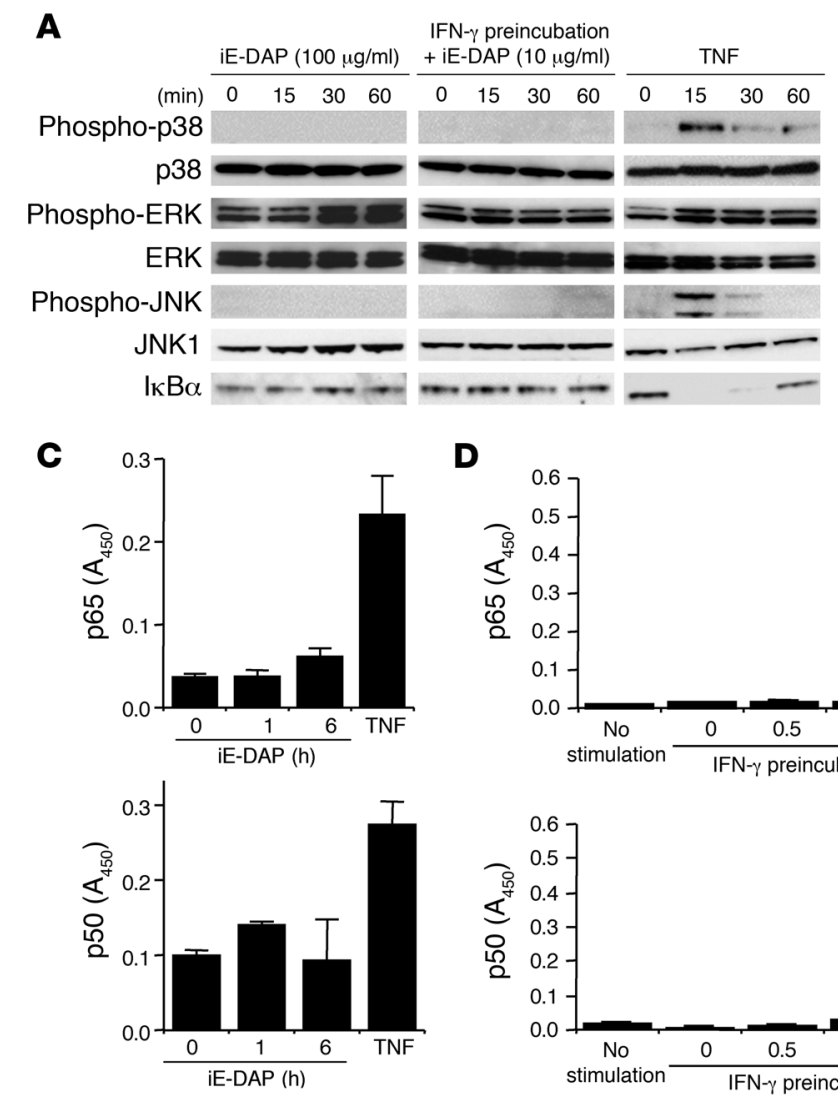

D
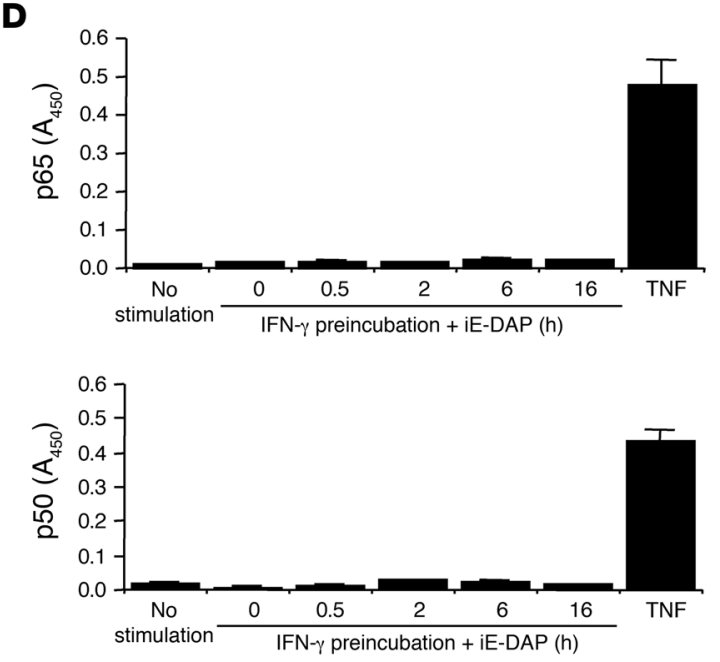

B iE-DAP IFN- $\gamma$ preincubation

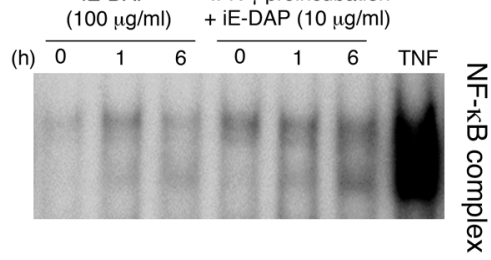

\section{Figure 2}

Activation of NF-KB and MAPK in HT-29 cells stimulated with iE-DAP. (A) HT-29 cells were either untreated or treated with $100 \mathrm{ng} / \mathrm{ml}$ of IFN- $\gamma$ (24 hours) and then stimulated with 10 or $100 \mu \mathrm{g} / \mathrm{ml}$ of iE-DAP. Whole cell extracts prepared from the stimulated cells at the indicated time points after stimulation with iE-DAP were then subjected to Western blot analysis. Extracts from HT-29 cells treated with $50 \mathrm{ng} / \mathrm{ml}$ TNF were used as positive controls. (B) NF-KB activation was assessed by EMSA. Nuclear extracts were prepared from IFN- $\gamma-$ untreated or IFN- $\gamma$-treated HT-29 cells stimulated with iE-DAP (10 or $100 \mu \mathrm{g} / \mathrm{ml}$ ) at the indicated time points. Nuclear extracts from TNF-treated (50 ng/ml) cells were used as a positive control. (C and D) Translocation of NF-KB subunits (p65, p50) in nuclear extracts was determined by Transfactor assay. Nuclear extracts from HT-29 cells treated with $50 \mathrm{ng} / \mathrm{ml}$ of TNF for 1 hour were used as positive controls for p65 and p50. HT-29 cells were pre-incubated with (D) or

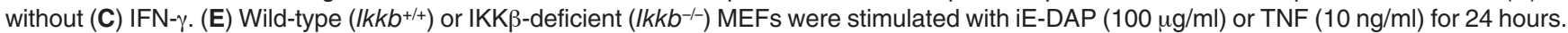
Cultured supernatants were subjected to an IP-10 assay. Results are expressed as means \pm SD. ${ }^{\star *} P<0.01$ compared with wild-type cells.

of the NF- $\kappa B$ construct in this artificial system. In further studies, we determined the capacity of iE-DAP to stimulate BM-derived dendritic cells (BMDCs) from NOD1-intact and NOD1-deficient mice to produce IL-6. Thus, as shown in Supplemental Figure 1B, NOD1-deficient BMDCs showed defective IL-6 production upon stimulation with iE-DAP, but not with muramyl dipeptide (MDP), as compared with NOD1-intact BMDCs. These data provide strong evidence that the $\mathrm{iE}-\mathrm{DAP}$ used in these studies activates NOD1, but not NOD2 or the various TLRs.

Having obtained these results, we explored the capacity of NOD1 to induce chemokine production by gastrointestinal epithelial cell lines in the absence and presence of proinflammatory cytokines. As shown in Figure 1A, production of IFN- $\gamma$-induced protein of $10 \mathrm{kDa}$ (CXCL10, also known as IP-10) and IFN-inducible T cell $\alpha$-chemoattractant (I-TAC, also known as CXCL11) by HT-29 cells (a colon epithelial cell line) was enhanced upon stimulation with the NOD1 ligand iE-DAP, whereas MDP activation of NOD2 in HT-29 cells did not increase production of these chemokines. In addition, NOD1 stimulation increased HT-29 cell production of IL-8 (CXCL8) but not a chemokine associated with Th2 responses, macrophage-derived chemokine (MDC, also known as CCL22). As shown in Supplemental Figure 1C, IP-10 levels obtained by the stimulation of HT-29 cells with synthesized iE-DAP was equivalent to the levels obtained by stimulation with iE-DAP obtained from a commercial source or FK-156 (9, 10). Moreover, induction of IP-10 production was seen in HT-29 cells stimulated with low doses of iEDAP (10-100 ng/ml), but only when iE-DAP was delivered together with lipofectamine $(10 \mathrm{ng} / \mathrm{ml}$ iE-DAP, $13 \pm 1 \mathrm{pg} / \mathrm{ml} ; 10 \mathrm{ng} / \mathrm{ml} \mathrm{iE-}$ DAP plus lipofectamine, $448 \pm 154 \mathrm{pg} / \mathrm{ml} ; 100 \mathrm{ng} / \mathrm{ml} \mathrm{iE}-\mathrm{DAP}, 14 \pm 1$ $\mathrm{pg} / \mathrm{ml} ; 100 \mathrm{ng} / \mathrm{ml}$ iE-DAP plus lipofectamine, $977 \pm 48 \mathrm{pg} / \mathrm{ml}$ ).

Since, as shown in Figure 1B, expression of NOD1 is enhanced by IFN- $\gamma$ but not by TNF (whereas the opposite is true of NOD2), we next measured production of IP-10 by HT-29 cells incubated for 24 hours with IFN- $\gamma$ prior to stimulation with NOD1 or NOD2 ligand for another 24 hours. As shown in Figure 1C, IFN- $\gamma$-precultured HT-29 cells exhibited an increased baseline secretion of Th1 chemokines (IP-10 and I-TAC) that was greatly enhanced by NOD1 ligand stimulation. Thus, in the case of IP-10, NOD1 ligand stimulation led to a massive increase in production that peaked at a level some 500-fold greater than that seen in cells not pretreated with 


Table 1
IP-10 production by HT-29 cells transfected with siRNAs specific
to RICK, p65, or p38
$\begin{array}{lcccc} & & & \\ \text { Parameter } & \text { Control } & \text { RICK } & \text { p65 } & \text { p38 } \\ \text { Without IFN- } \gamma & 14.1 \pm 0.8 & 3.1 \pm 0.2^{\mathrm{A}} & 11.9 \pm 1.3 & 14.0 \pm 1.0 \\ \text { With IFN- } \gamma & 249.0 \pm 8.0 & 58.8 \pm 7.1^{\mathrm{A}} & 191.9 \pm 16.7 & 238.3 \pm 9.9 \\ \text { TNF } & 22.3 \pm 0.5 & \text { Not done } & 6.3 \pm 0.3^{\mathrm{A}} & 13.9 \pm 0.3^{\mathrm{B}}\end{array}$

HT-29 cells were transfected with $20 \mathrm{nM}$ of siRNAs specific to RICK, p38, or p65 and then stimulated with iE-DAP (10 or $100 \mu \mathrm{g} / \mathrm{ml})$ in the presence or absence of IFN- $\gamma(100 \mathrm{ng} / \mathrm{ml})$. Cells stimulated with TNF alone $(50 \mathrm{ng} / \mathrm{ml})$ were used as controls. Cultured supernatants were analyzed for IP-10 production; data are shown as $\mathrm{ng} / \mathrm{ml}$. Results are expressed as means \pm SD and are representative of 2 studies. AP $<0.01 ;{ }^{B} P<0.05$ compared with cells transfected with control siRNA

IFN- $\gamma$, whereas MDP stimulation did not induce secretion above the baseline level obtained in unstimulated cells.

As shown in Supplemental Figure 2, similar data were obtained in the study of AGS cells (a gastric epithelial cell line), in that the NOD1 but not NOD2 ligand stimulated secretion of Th1-associated chemokines above baseline in both cells pretreated and not pretreated with IFN- $\gamma$. In addition, once again, greatly augmented baseline and stimulated secretion was observed in the IFN- $\gamma$-pretreated cells. Taken together, these data indicate that NOD1 ligand stimulation of epithelial cells enhances the production of chemokines in the presence or absence of IFN- $\gamma$, but such enhancement is limited to those chemokines associated with cytokines that participate in the Th1 response.

NOD1-induced Th1 chemokine production is dependent on RICK and is largely independent of $N F-\kappa B$ activation. We next turned our attention to the signaling pathway involved in NOD1-induced chemokine production in HT-29 cells and AGS cells. Previous studies have established that NOD2 activation results in interactions between the CARD domain of the NOD molecule and the CARD domain of a downstream effector molecule, the serine-threonine kinase RICK, and the activated RICK thus generated activated NF- $\mathrm{BB}$ $(1,2,4,5,14)$. In addition, it has been shown that NOD2, acting through TAK-1, activates elements of the MAPK pathway, including $\mathrm{p} 38$, ERK, and JNK $(1,15)$. Several lines of evidence have been presented supporting the idea that a similar, if not identical, signaling pathway applies to NOD1 $(16,17)$. However, for reasons discussed above (see Introduction) we decided to re-examine this concept. Thus, in initial studies we determined whether stimulation of epithelial cells with NOD1 ligand (iE-DAP) did in fact lead to the appearance of activated NF-KB or MAPK components. As shown in Figure 2A, stimulation of HT-29 cells with NOD1 ligand with and without IFN- $\gamma$ pretreatment did not lead to the activation of NF-кB or p38/JNK kinases, since neither degradation of I $\kappa \mathrm{B} \alpha$ nor expression of phosphorylated forms of p38 and JNK was detected in the whole cell extracts. However, NOD1 ligand stimulation in the absence but not in the presence of IFN- $\gamma$ led to the activation of ERK. In positive control studies, we showed that stimulation of cells with TNF led to easily detectable degradation of I $\mathrm{B} \alpha$ and activation of MAPKs (Figure 2A).

In further studies we explored the involvement of NF- $\mathrm{BB}$ activation in NOD1 signaling using assays of factor activation and nuclear translocation. As shown in Figure 2B, EMSAs of nuclear extracts of NOD1 ligand-stimulated HT-29 cells detected a rela-

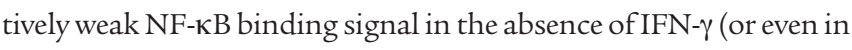
the presence of IFN- $\gamma$ ) compared with the signal obtained in TNFtreated HT-29 cells. In addition, as shown in Figure 2, C and D, and Supplemental Figure 3, semiquantitative "Transfactor" binding assays (see Methods) (13) of nuclear extracts of NOD1 ligandstimulated HT-29 cells did not give rise to NF-кB subunit signals significantly above baseline (p65, p50, p52, or RelB) in cells stimulated with or without IFN- $\gamma$, whereas identical assays of nuclear extracts of TNF-treated HT-29 cells (p65 and p50) and Raji cells (p52 and RelB) gave rise to easily detectable NF-кB subunit signals. Thus, while evidence of weak NF-KB activation by NOD1 ligand stimulation was obtained with the sensitive ${ }^{32} \mathrm{P}$-labeled probe-based EMSA method, no evidence of such activation was detected in the Transfactor binding assay. Finally, as shown in Supplemental Figure 4, a similar picture emerged from studies of NOD1 stimulation of AGS cells, where again NF-кB activation was not detected by the Transfactor assay.

In a second set of studies to determine which of previously established signaling components of NOD1 signaling were relevant to chemokine production, HT-29 cells were incubated with various inhibitors specific to these pathways, including PD98059 (ERK inhibitor), SB203580 (p38 and RICK inhibitor) (18), SP600125 (JNK inhibitor), or BAY11-7082 (NF-אB inhibitor) for 1 hour and then stimulated with NOD1 ligand. As shown in Supplemental Figure 5A, addition of the p38 and RICK inhibitor SB203580 to cultures led to reduced IP-10 production by both IFN- $\gamma$-treated and -untreated HT-29 cells in a dose-dependent manner. In contrast, addition of an ERK or JNK inhibitor had no inhibitory effects on IP-10 production, and addition of the NF- $\mathrm{KB}$ inhibitor BAY11-7082 was also not inhibitory except at the highest dose $(25 \mu \mathrm{M})$, when it was partially inhibitory. In control experiments, $20 \mu \mathrm{M}$ of each inhibitor effectively reduced IP-10 production by HT-29 cells stimulated with TNF (Supplemental Figure 5B); thus, the dose of inhibitors used was sufficient to see inhibitory effects.

In additional studies to evaluate the role of the aforementioned signaling components in NOD1-mediated chemokine production, we transfected HT-29 cells with control, p38, p65, or RICK siRNA and then stimulated the cells with NOD1 ligand. As shown in Table 1, transfection of RICK-specific siRNA into cells either not pre-incubated or pre-incubated with IFN- $\gamma$ greatly reduced IP-10 production by HT-29 cells. In contrast, transfection of p38 siRNA had no effect and transfection of p65 siRNA had a small effect that was not statistically significant. Finally, we determined the ability of NOD1 ligand to induce mouse embryonic fibroblasts (MEFs) lacking IKK $\beta$ (19) to produce IP-10. As shown in Figure 2E, NOD1 ligand induced wild-type MEFs and IKK $\beta$-deficient MEFs to produce comparable levels of IP-10, whereas TNF stimulation of IKK $\beta$ deficient MEFs resulted in greatly reduced IP-10 production.

Taken together, this series of studies indicates that NOD1 ligand signaling and induction of chemokines associated with the Th1 response in HT-29 cells is dependent on RICK activation and that NF-кB and MAPKs play, at best, minor roles in such signaling/ induction, at least with respect to mucosal epithelial cells.

RICK induced by NOD1 interacts with TRAF3. Having established that NOD1 induction of IP-10 depends on its downstream effector molecule RICK but not necessarily on NF- $\mathrm{KB}$, we next turned our attention to the molecular interactions that might alternatively facilitate RICK induction of IP-10. Here we considered the possibility that TRAF3 might play an important role, since this adaptor protein negatively regulates NF- $\kappa \mathrm{B}$ activation and, via 

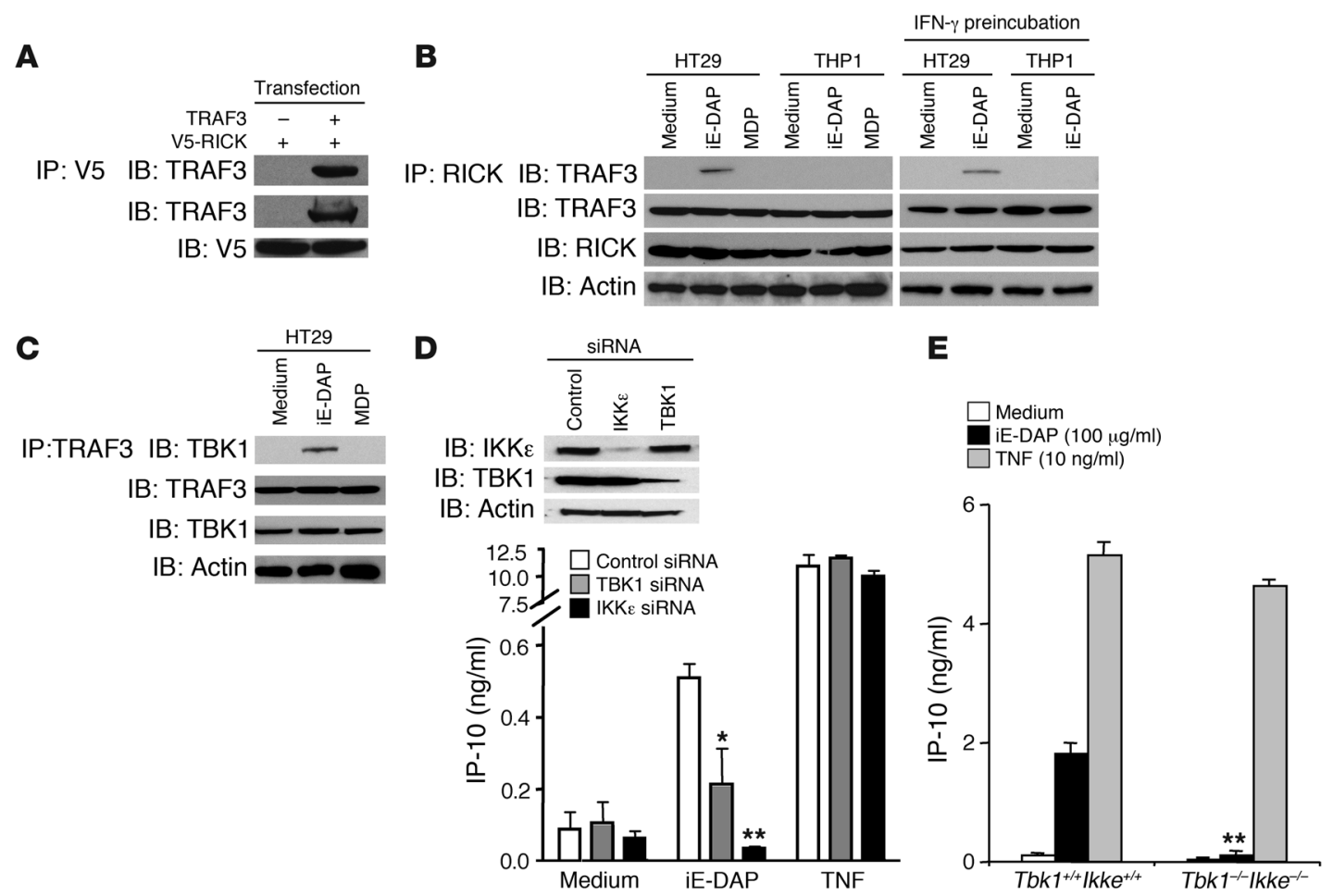

\section{Figure 3}

NOD1-induced interaction of TRAF3 with RICK or TBK1. (A) HEK293 cells were transfected with $2 \mu \mathrm{g}$ of V5-tagged RICK cDNA and/or $2 \mu \mathrm{g}$ of TRAF3 cDNA. Lysates were immunoprecipitated with anti-V5 beads followed by immunoblotting with anti-TRAF3 Ab. (B and C) Physical interaction between RICK and TRAF3 (B) or between TRAF3 and TBK1 (C). HT-29 cells or THP1 cells untreated (B, left panel) or treated with IFN- $\gamma(100 \mathrm{ng} / \mathrm{ml})$ (right panel) for 24 hours were left unstimulated (medium, $100 \mu \mathrm{g} / \mathrm{ml}$ ) or were stimulated with iE-DAP (10 $\mu \mathrm{g} / \mathrm{ml})$ or MDP (100 $\mu \mathrm{g} / \mathrm{ml}$ ) for 1 hour. Lysates were immunoprecipitated with anti-RICK Ab or anti-TRAF3 Ab, followed by immunoblotting with anti-TRAF3 Ab or anti-

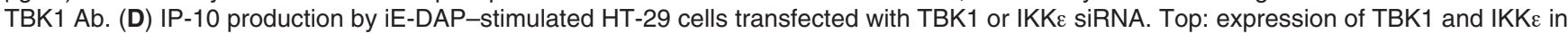
HT-29 cells transfected with TBK1 or IKK siRNA. Bottom: IP-10 production of transfected cells. HT-29 cells were transfected with TBK1 siRNA, IKKE siRNA, or control siRNA (20 nM each) and after 24 hours cells were cultured for a further 48 hours with iE-DAP (100 $\mu \mathrm{g} / \mathrm{ml})$ or TNF (100

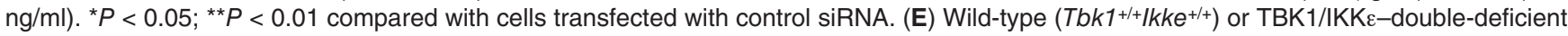
$\left(\right.$ Tbk $\left.1^{--I} / k^{-/-}\right)$MEFs $\left(10^{6} / \mathrm{ml}\right)$ were stimulated with iE-DAP $(100 \mu \mathrm{g} / \mathrm{ml})$ or TNF $(10 \mathrm{ng} / \mathrm{ml})$ for 24 hours. Cultured supernatants were subjected to an IP-10 assay. Results are expressed as mean \pm SD. ${ }^{* *} P<0.01$ compared with wild-type cells.

TBK1/IKKe activation, induces IRFs that have been implicated in type I IFN induction of IP-10 $(20,21)$. To explore this possibility, we first performed co-immunoprecipitation studies to determine whether RICK physically interacts with TRAF3. As shown in Figure 3A, immunoprecipitation of whole cell extracts of HEK293 cells overexpressing V5-tagged RICK and TRAF3 cDNA constructs with anti-V5-conjugated beads followed by immunoblotting with anti-TRAF3 showed that RICK does indeed bind to TRAF3. Control studies in which TRAF2-RICK interactions were evaluated proved negative (data not shown). In addition, as shown in Figure 3B, similar and more definitive results were obtained by co-immunoprecipitation of endogenous RICK and TRAF3 in extracts of NOD1 ligand-stimulated HT-29 cells but not NOD2 ligand-stimulated HT-29 cells. Physical interaction between RICK and TRAF3 was also seen in HT-29 cells pretreated with IFN- $\gamma$ and stimulated with NOD1 ligand. In contrast, stimulation of THP1 cells (a monocytic cell line) with NOD1 or NOD2 ligand did not result in co-immunoprecipitation of endogenous RICK and TRAF3 even in cells prestimulated with IFN- $\gamma$, which enhances expression of NOD1 (6). Thus, NOD1 activation induces interaction between RICK and TRAF3 in epithelial cells rather than in APCs. Finally, as shown in Supplemental Figure 6A, THP1 cells failed to produce IP-10 in response to stimulation with NOD1 ligand, strongly suggesting that NOD1-induced interaction between RICK and TRAF3 plays an important role in the production of this chemokine.

In further studies to determine the effect of the interaction of RICK with TRAF3 on TRAF3 or on TRAF3 signaling, we showed first that this interaction is not likely to result in phosphorylation of TRAF3 by RICK because NOD1 ligand-stimulated HT-29 cells produce IP-10 after transfection with a plasmid expressing RICK but lacking kinase activity (data not shown). Nevertheless, we did find that the interaction led to activated TRAF3, since, as shown in the co-immunoprecipitation study in Figure 3C, upon stimulation of HT-29 cells with NOD1 ligand but not NOD2 ligand, TRAF3 physically interacted with TBK1, a known downstream factor of TRAF3. TBK1 along with IKKe led to the activation of IRFs necessary for type I IFN induction including IRF7, an IRF shown below to be activated by NOD1 stimulation (Figure 4).

On the basis of the above studies, we reasoned that if indeed the RICK interaction with TRAF3 and the TRAF3 interaction with TBK1 are relevant to NOD1-induced IP-10 synthesis, then interference with TBK1 and IKKe function would affect such synthe- 

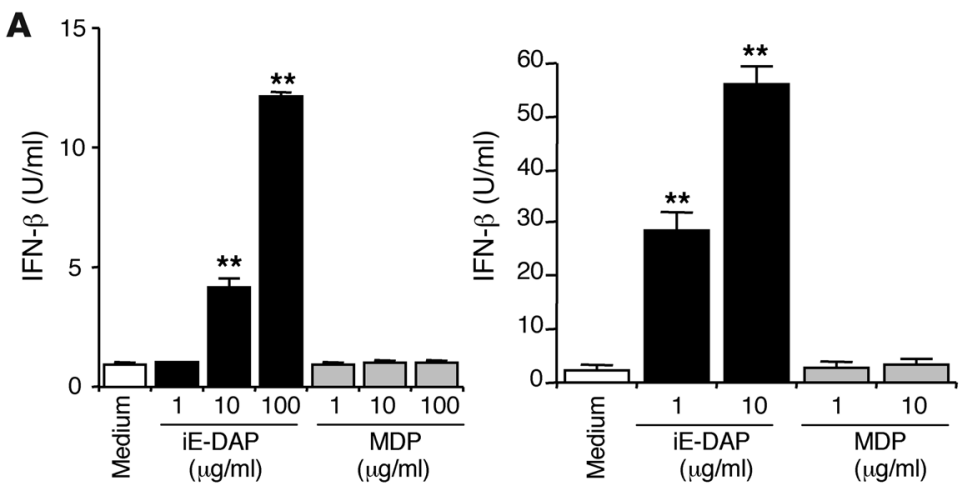

B
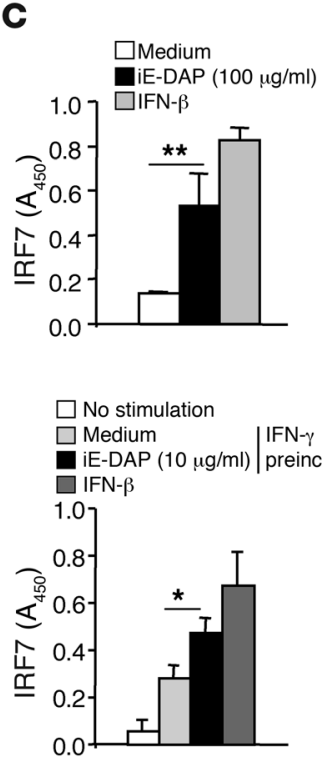

D
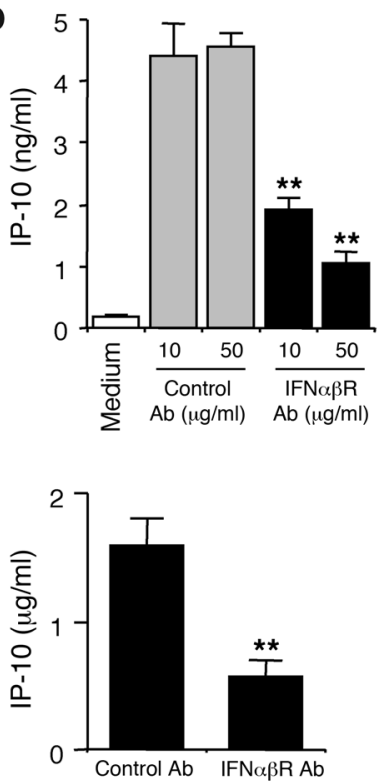
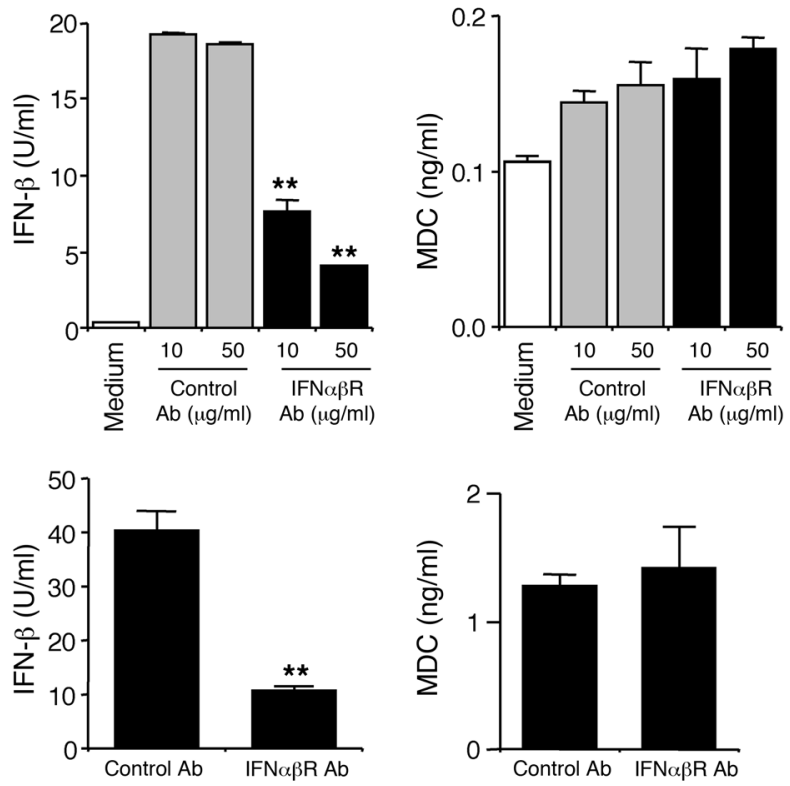

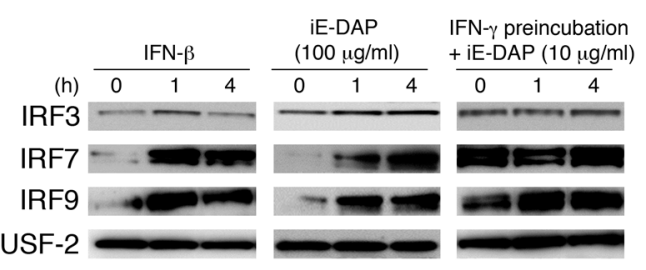

Figure 4

Type I IFN signaling induced by NOD1. (A) IFN- $\beta$ production by HT-29 cells stimulated with NOD1 ligand. HT-29 cells with (right) or without (left) pre-incubation with $100 \mathrm{ng} / \mathrm{ml}$ of IFN- $\gamma$ (24 hours) were stimulated with NOD ligands (iE-DAP or MDP) for 12 hours, after which culture supernatants were collected and subjected to IFN- $\beta$ assay. ${ }^{* *} P<0.01$ compared with cells cultured with medium alone. (B) Expression of IRF3, IRF7, and IRF9 in nuclear extract from HT-29 cells. USF-2 expression was used as a loading control. Nuclear extracts from HT-29 cells treated with IFN- $\beta$ were used as positive controls. (C) Expression of IRF7 in nuclear extracts was determined by Transfactor assay. Nuclear extracts from HT-29 cells treated with IFN- $\beta$ for 1 hour were used as positive controls. HT-29 cells with (bottom) or without (top) pre-incubation with IFN- $\gamma$ were stimulated with iE-DAP $(10$ or $100 \mu \mathrm{g} / \mathrm{ml})$ for 4 hours, at which point nuclear extracts were prepared. ${ }^{*} P<0.05 ;{ }^{* *} P<0.01$. (D) IP-10 production induced by NOD1 activation depends upon type I IFN signaling. HT-29 cells were pretreated with control Ab or neutralizing anti-IFN $\alpha \beta R$ antibody (top, 10 or $50 \mu \mathrm{g} / \mathrm{ml}$; bottom, $50 \mu \mathrm{g} / \mathrm{ml}$ ) for 24 hours before stimulation with NOD1 ligand. Cultured supernatants were subjected to IP-10, IFN- $\beta$, and MDC assays (top: HT-29 cells without IFN- $\gamma$ pre-incubation; bottom: HT-29 cells pre-incubated with IFN- $\gamma$ ). Results are expressed as mean $\pm \mathrm{SD} .{ }^{* \star} P<0.01$ compared with cells treated with control $\mathrm{Ab}$.

sis. To test this possibility, we stimulated HT-29 cells with NOD1 ligand in the presence of TBK1 or IKKE siRNA and control siRNA. As shown in Figure 3D, Western blot analysis of cell extracts of stimulated cells showed that the siRNAs employed had substantial but nevertheless incomplete downregulatory effects on the target components. In addition, as shown in Figure 3D, both the TBK1and IKKE-specific siRNAs inhibited NOD1 ligand-induced IP-10 production in approximate proportion to the inhibition of the target components; in contrast, TNF-induced IP-10 production was not reduced in HT-29 cells transfected with TBK1-or IKKespecific siRNAs. Finally, to further verify that both TBK1 and IKKE are part of the NOD1-mediated signaling pathway involved in IP-10 production, we determined NOD1-induced IP-10 produc- tion in MEFs lacking both TBK1 and IKKe (22). As shown in Figure 3E, NOD1 ligand-induced IP-10 production was severely impaired in MEFs lacking both TBK1 and IKKe as compared with wild-type MEFs, whereas comparable MEFs showed no difference in TNF-induced IP-10 production. Taken together, these data provide strong evidence that the RICK/TRAF3/TBK1/IKKe interaction is indeed involved in the NOD1 stimulation pathway, which results in IP-10 production.

It has been shown that TRAF3 activation leads to inhibition of NF- $\kappa \mathrm{B}$ activation (23). Thus, NOD1-induced binding of RICK to TRAF3 provides a possible explanation for why NOD1 signaling results in only marginal NF-KB activation. As shown in Supplemental Figure $6 \mathrm{~B}$, this possibility is supported by the fact that 
A

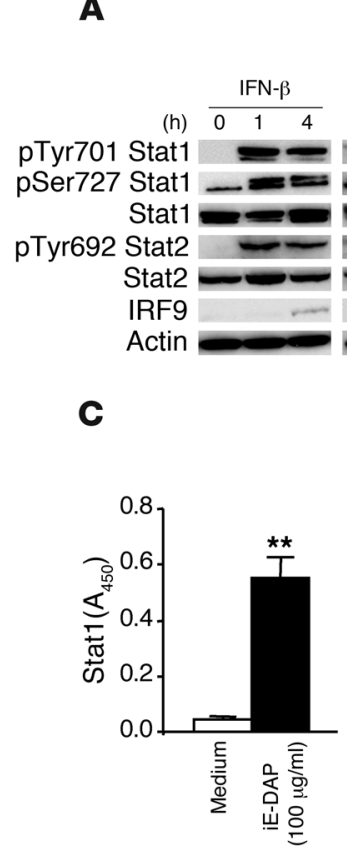

B

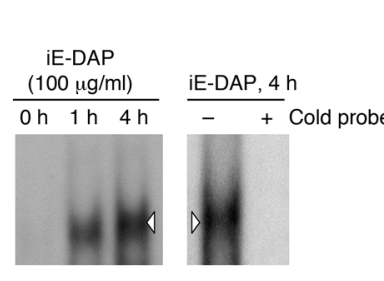

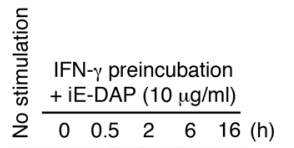
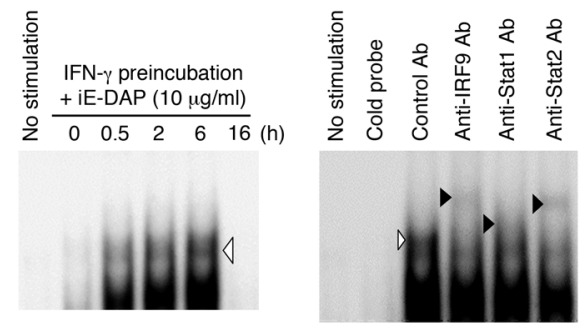

\section{Figure 5}

ISGF3-dependent production of IP-10 in HT-29. (A) Expression of Stat1, Stat2, and IRF-9 in whole cell extracts of HT-29 cells. Middle and right panels show immunoblots from HT-29 cells not treated with IFN- $\gamma$ and treated with IFN- $\gamma$, respectively. Extracts from cells treated with IFN- $\beta$ were used as positive controls. (B) Nuclear translocation of ISGF3 by NOD1 activation. Nuclear extracts were prepared from IFN- $\gamma-$ untreated (left 2 blots) or IFN- $\gamma$-treated (middle) HT-29 cells stimulated with iE-DAP. Nuclear extracts from IFN- $\gamma$-treated HT-29 cells 2 hours after stimulation with iE-DAP were used for Supershift assays (right). White arrowheads indicate position of the ISGF3 complex. Black arrowheads indicate position of supershifted complexes. (C) Expression of Stat1 in nuclear extracts was determined by Transfactor assay. HT-29 cells pre-incubated or not with IFN- $\gamma$ were stimulated with iE-DAP for 4 hours, at which point nuclear extracts were prepared. ${ }^{* *} P<0.01$ compared with cells without stimulation. (D) Production of IP-10 and IFN- $\beta$ by HT-29 cells transfected with Stat1 or Stat2 siRNA. HT-29 cells were transfected with control vector, Stat1 siRNA-expressing vector, or Stat2 siRNA-expressing vector and then stimulated with iE-DAP in the absence of IFN- $\gamma$. Cells were then lysed, and the whole lysates obtained were subjected to Western blot analysis. Production of IP-10 and IFN- $\beta$ by HT-29 cells transfected with Stat1 or Stat2 siRNA is shown in the graphs. Results are expressed as mean \pm SD. ${ }^{\star \star} P<0.01$ compared with cells transfected with control vector. Results shown are representative of 2 similar studies.

HT-29 cells cotransfected with an NF-אB-luciferase reporter construct along with either of 2 different TRAF3-specific siRNAs exhibited a significantly increased luciferase signal when stimulated with NOD1 ligand as compared with cells transfected with the NF-kB-luciferase construct alone.

IP-10 production induced by NOD1 activation depends upon type I IFN. The above data showing that NOD1 signaling proceeds through an alternative signaling pathway involving TRAF3 as well as the generation of TBK/IKKe led us to ask next whether this pathway results in the production of type I IFN, a cytokine that has been shown to induce the production of IP-10 via the generation of ISGF3. The latter is a molecular complex consisting of p-Stat1, p-Stat2, and IRF9 that initiates transcription of IP-10 via binding to an IFN-stimulated response element (ISRE) in the IP-10 promoter $(24,25)$.

In an initial test of this hypothesis, we determined whether NOD1 ligand induces HT-29 cells to produce IFN- $\beta$. As shown in Figure 4A, NOD1 stimulation of HT-29 cells led to the production of increased amounts of IFN- $\beta$ in both the absence and presence of IFN- $\gamma$, whereas NOD2 ligand had no such effect. In addition, enhanced production of IFN- $\beta$ was also seen in HT-29 cells stimulated with low doses of iE-DAP in combination with lipofection $(10 \mathrm{ng} / \mathrm{ml}$ iE-DAP plus lipofectamine, $1.3 \pm 0.1 \mathrm{U} / \mathrm{ml}$;
$100 \mathrm{ng} / \mathrm{ml}$ iE-DAP plus lipofectamine, $6.5 \pm 0.7 \mathrm{U} / \mathrm{ml})$. Since such IFN- $\beta$ production requires nuclear translocation and transactivation by IRF3 and/or IRF7 $(26,27)$, we then determined whether stimulation by NOD1 ligand enhances the expression of these transcription factors. As shown in Figure 4B, nuclear extracts of HT-29 cells stimulated by NOD1 ligand or IFN- $\beta$ as a positive control exhibited greatly increased expression of IRF7 and a lesser increase in IRF3 expression when subjected to Western blot analysis. To quantify this NOD1 stimulation effect on IRF7, we subjected nuclear extracts of NOD1 ligand-stimulated cells to the Transfactor assay, again using nuclear extracts from IFN- $\beta$ treated cells as positive controls. As shown in Figure 4C, in cells stimulated by NOD1 ligand, nuclear translocation of IRF7 was significantly enhanced as assessed by this technique. In further control studies, we compared the production of IFN- $\beta$ and IRF7 induced by NOD1 ligand with that induced by poly (I:C) (double-stranded RNA [dsRNA]) stimulation. As shown in Supplemental Figure $7 \mathrm{~A}$, whereas dsRNA was a considerably better inducer of IFN- $\beta$ production than was iE-DAP, these stimuli induced nearly comparable amounts of IRF7. In contrast, stimulation with TNF did not induce IFN- $\beta$ production or IRF7 transactivation. IFN- $\beta$ production induced by dsRNA but not iE-DAP was partially mediated 

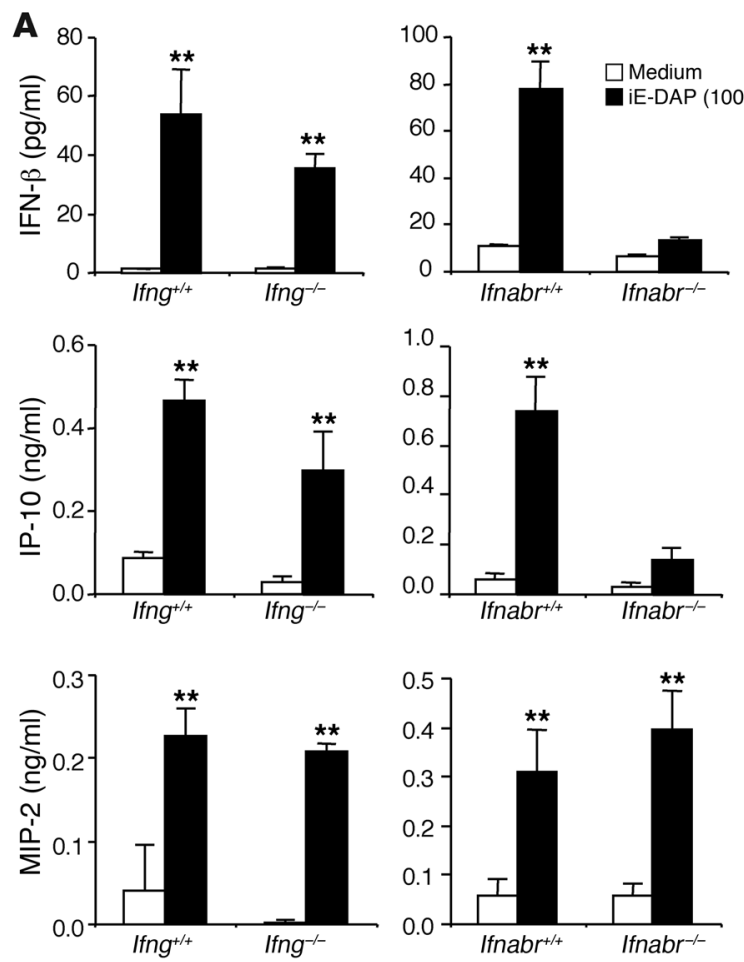
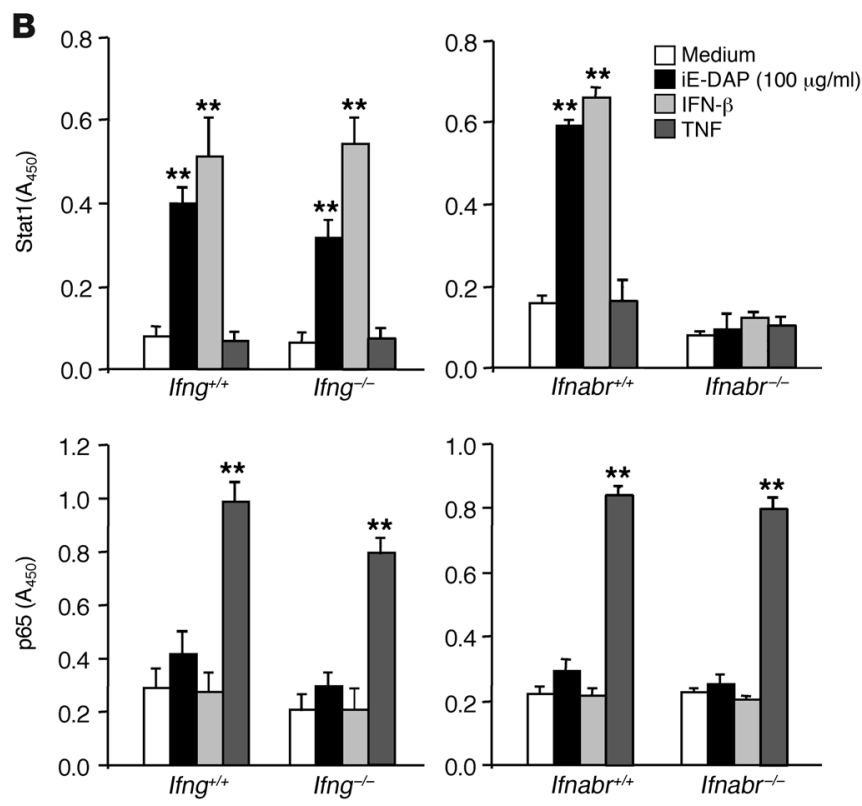

Figure 6

Activation of ISGF3 in primary epithelial cells by stimulation with NOD1 ligand. (A) Primary epithelial cells were isolated from the small intestine of IFN- $\gamma$-intact $\left(\right.$ Ifng $\left.{ }^{+/+}\right)$and IFN- $\gamma$-deficient $\left(\right.$ Ifng $\left.{ }^{-/}\right)$mice. Primary epithelial cells were isolated from the small intestine of IFN $\alpha \beta R$-intact $\left(\right.$ Ifnabr $\left.r^{+/+}\right)$and IFN $\alpha \beta R$-deficient $\left(I f n a b r^{-1}\right)$ mice. Primary epithelial cells $\left(2 \times 10^{6} / \mathrm{ml}\right)$ were stimulated with iE-DAP $(100 \mu \mathrm{g} / \mathrm{ml})$ for $24 \mathrm{hours}$. Cultured supernatants were harvested and assayed for the presence of IP-10, IFN- $\beta$, and MIP-2 using ELISA. (B) Nuclear translocation of Stat1 and p65. Cells were stimulated with iE-DAP $(100 \mu \mathrm{g} / \mathrm{ml})$, and then nuclear extracts were prepared. Cells were stimulated with iE-DAP for 1 hour for p65 assay and for 4 hours for Stat 1 assay. Nuclear extracts isolated from cells stimulated with IFN- $\beta(1,000$ U/ml) or TNF (100 ng/ml) were used as positive controls. Results are expressed as mean \pm SD. Results shown are representative of 2 similar studies. ${ }^{* *} P<0.01$ compared with unstimulated cells.

by NF- $\kappa$ B activation, since, as shown in Supplemental Figure 8A, addition of BAY11-7082 (NF- $\mathrm{KB}$ inhibitor) caused considerable reduction in dsRNA-induced IFN- $\beta$ production.

In a final study to establish the role of type I IFN in NOD1 induction of IP-10, we determined whether alterations in type I IFN signaling would affect IP-10 production. As shown in Figure $4 \mathrm{D}$, neutralization of type I IFN signaling by an IFN- $\alpha \beta$ receptor (IFN $\alpha \beta R$ ) $m A b$ decreased IP-10 production in a dose-dependent manner but had no effect on the production of the Th2 chemokine MDC. Moreover, as shown in Supplemental Figure 8B, stimulation of HT- 29 cells with IFN- $\beta$ increased IP- 10 production in a dose-dependent manner. It should be noted that complete inhibition of IFN- $\beta$ production was not obtained by addition of an IFN $\alpha \beta R$ mAb. This may be due to the presence of intracellular type I IFNR (28). Taken together, these data provide strong evidence that NOD1 induction of IFN- $\beta$ synthesis does in fact result in the production of IP- 10 .

NOD1 activation induces formation and nuclear translocation of ISGF3. In further studies of possible NOD1 induction of IP-10 via an IFN- $\beta$-mediated pathway, we determined whether NOD1 activation leads to the generation of ISGF3, the aforementioned transcription factor of IP-10. In particular, we analyzed the expression of Stat 1 , Stat 2 , and IRF proteins in HT-29 cells stimulated with NOD 1 ligand (or with IFN- $\beta$ as a positive control) by immunoblotting whole cell extracts of stimulated cells. As shown in Figure 5A, such stimulation of HT-29 cells, whether pre-incubated with IFN- $\gamma$ or not, led to enhanced expression of p-Stat 1 (at both serine and tyrosine sites) and p-Stat2. The enhanced baseline expression of activated Stat 1 and Stat 2 in cells subject to IFN- $\gamma$ pre-incubation did not obscure the increased expression of these factors induced by NOD1 ligand. Finally, as shown in Supplemental Figure 7B, phosphorylation of Stat 1 and Stat 2 was seen in HT-29 cells stimulated with dsRNA but not with TNF.

In parallel studies we determined the expression of IRF proteins by immunoblotting whole cell and/or nuclear extracts. As shown in Figure 4B and Figure 5A, while stimulation of HT-29 cells in the absence of IFN- $\gamma$ with NOD1 ligand did not lead to detectable expression of IRF9 in whole cell extracts, it clearly led to increased expression of IRF9 in nuclear extracts. In addition, such activation led to expression of IRF9 in NOD1-stimulated cells pre-incubated with IFN- $\gamma$.

In a further analysis of ISGF3 translocation, we performed EMSAs on nuclear extracts using a ${ }^{32} \mathrm{P}-$ labeled ISRE probe. As shown in Figure 5B, NOD1 ligand stimulation of HT-29 cells induced an ISRE-binding complex at 1 and 4 hours after stimulation in cells not pre-incubated with IFN- $\gamma$. In addition, as shown in Figure 5B, such stimulation of IFN- $\gamma$-pre-incubated HT-29 cells induced a binding complex supershifted with antibodies to Stat 1 , 

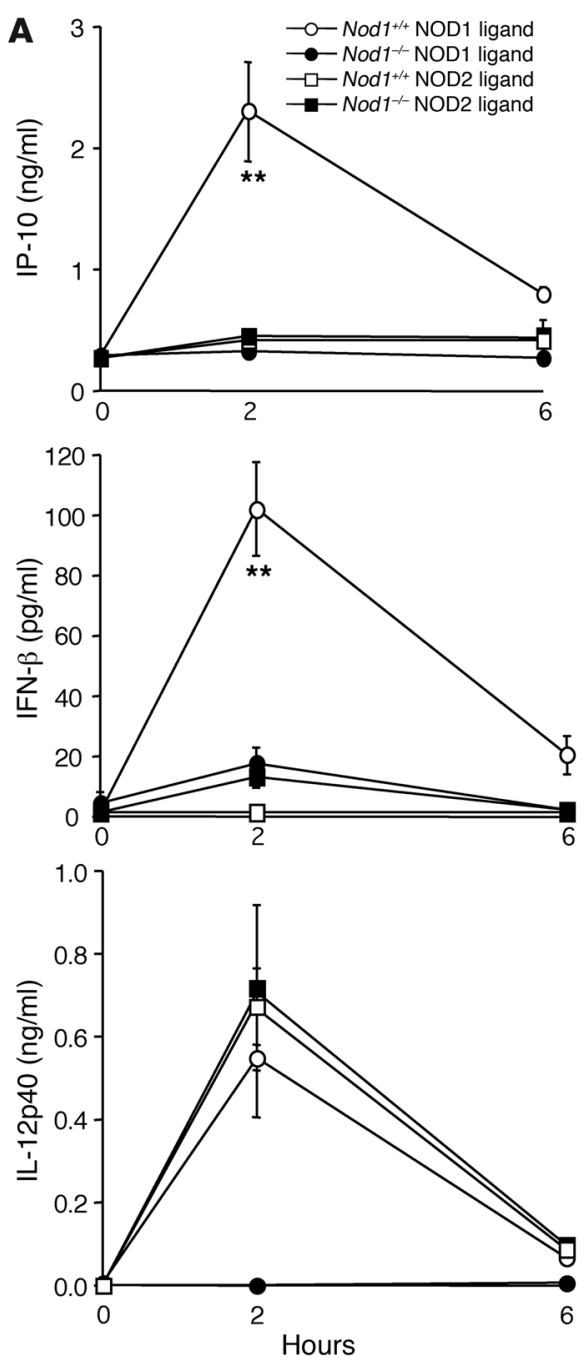
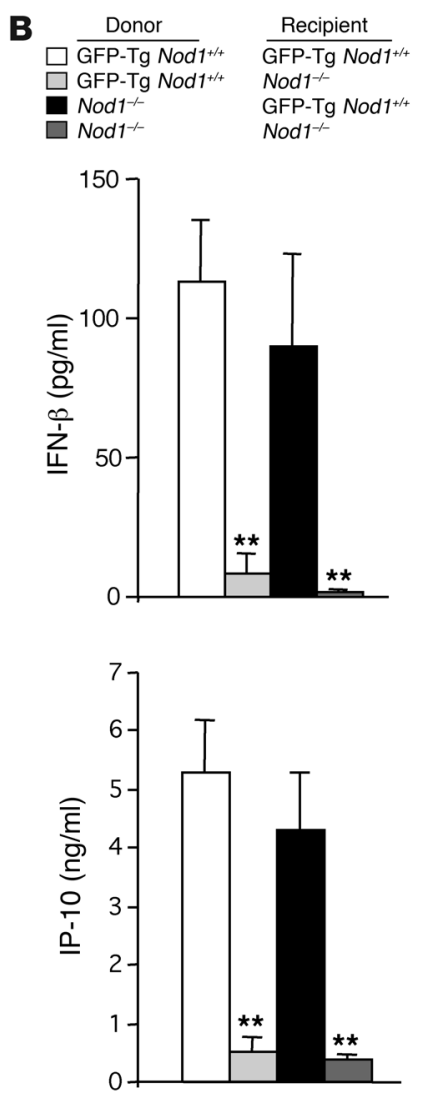

\section{Figure 7}

NOD1 expressed in nonhematopoietic lineage cells is responsible for the production of IP-10 and IFN- $\beta$. (A) Production of IP-10, IFN- $\beta$, and IL-12p40. NOD1-intact $\left(\mathrm{Nod1}^{+/+}\right)$and NOD1-deficient (Nod1-/-) mice were administered NOD1 ligand (FK156; $200 \mu \mathrm{g}$ ) or NOD2 ligand (MDP; $200 \mu \mathrm{g}$ ) by intraperitoneal injection. Sera were obtained from these mice at the indicated time points. ${ }^{* \star} P<0.01$ compared with other groups. (B) BMchimeric mice were created as described in the text. Mice were reconstituted with $2 \times 10^{6} \mathrm{BM}$ cells. Sera were obtained from these BM-chimeric mice 2 hours after intraperitoneal administration of NOD1 ligand. Results are expressed as means $\pm \mathrm{SD}$. ${ }^{* *} P<0.01$ compared with NOD1-intact (GFP-Tg) mice reconstituted with BM cells from GFP-Tg mice. Results shown are representative of 2 studies, and each group consists of 4 mice.

the ISGF3 signaling pathway, and whether IP-10 synthesis is dependent on this pathway. In initial control studies (Figure 5D), we showed that transfection of resting HT-29 cells with vectors expressing Stat 1 and Stat2 siRNAs do in fact substantially reduce the expression of Stat 1 and Stat2, respectively, in whole extracts of these cells 48 hours after the transfection. We then transfected control, Stat 1 siRNA, or Stat2 siRNA into HT-29 cells and stimulated the cells with NOD1 ligand. As shown in Figure 5D and Supplemental Figure 10A, transfection of Stat 1 or Stat2 siRNA reduced IP-10 production upon stimulation with NOD1 ligand whether or not cells were preincubated with IFN- $\gamma$. In contrast, no change was seen in production of the Th2 chemokine MDC following transfection of these vectors (data not shown). Finally, as shown in Supplemental Figure 10B, NOD1 ligand stimulation of AGS cells not pre-incubated with IFN- $\gamma$ exhibited reduced IP-10 production fol-

Stat2, and IRF9. In contrast, nuclear extracts from HT-29 cells stimulated with NOD1 ligand using a probe consisting of the IFN- $\gamma$ activated site did not yield a band indicative of the presence of nuclear Stat 1 homodimer (data not shown). To verify this NOD1 stimulation effect on ISGF3, we also subjected nuclear extracts of NOD1 ligand-stimulated cells to a Stat1-specific Transfactor Assay. As shown in Figure 5C, in cells stimulated by NOD1 ligand in the presence and absence of IFN- $\gamma$, nuclear translocation of Stat 1 was significantly enhanced, as assessed by this technique. Taken together, these data show that NOD1 activation by its ligand induces nuclear translocation of ISGF3.

The above data show quite clearly that NOD1 ligand stimulation of HT-29 cells is associated with increased expression of all 3 components of ISGF3 (Stat1, Stat2, and IRF9) whether or not cells were pre-incubated with IFN- $\gamma$, and that such expression was accompanied by nuclear translocation of ISGF3. As shown in Supplemental Figure 9, in confirmation of some of these findings, NOD1 ligand stimulation of AGS cells also led to activation of both Stat1 and Stat2.

Production of Th1 chemokines mediated by NOD1 depends on the ISGF3 signaling pathway. In a final series of in vitro studies using gastrointestinal cell lines, we used a gene-silencing approach to determine whether NOD1 ligand signaling is associated with activation of lowing transfection of Stat 1 siRNA and Stat2 siRNA vectors. As shown in Figure 5D and Supplemental Figure 10A, this reduction of IP-10 production by transfection of Stat 1 siRNA and Stat 2 siRNA was not due to off-target effects, since knockdown of Stat 1 and Stat 2 reduced IFN- $\beta$ production by HT- 29 cells regardless of whether cells were pretreated with IFN- $\gamma$. Thus, these data provide strong evidence that NOD1 activation of the ISGF3 pathway results in the production of chemokines associated with the Th1

IFN- $\beta$ and IP-10 production by primary cells stimulated with NOD1 ligand. We next addressed whether NOD1 activation results in enhanced IFN- $\beta$ production by primary intestinal epithelial cells as well as intestinal epithelial cell lines. For this purpose, we isolated primary epithelial cells from the small intestine and then time depending on the response measured (see Methods). Cells isolated from IFN- $\gamma$-deficient mice (29) or IFN $\alpha \beta R$-deficient mice (30) were also studied to address the role of IFNs in NOD1 activation. As shown in Figure 6A, NOD1 ligand stimulation of primary epithelial cells led to increased production of IFN- $\beta$, IP-10, and MIP- 2 in cells from both IFN- $\gamma$-intact and IFN- $\gamma$-deficient mice. In addition, as shown in Figure 6B, NOD1 ligand stimulation also led to markedly enhanced nuclear translocation of response such as IP-10 in the presence or absence of IFN- $\gamma$. stimulated these cells with NOD1 ligand for various lengths of 

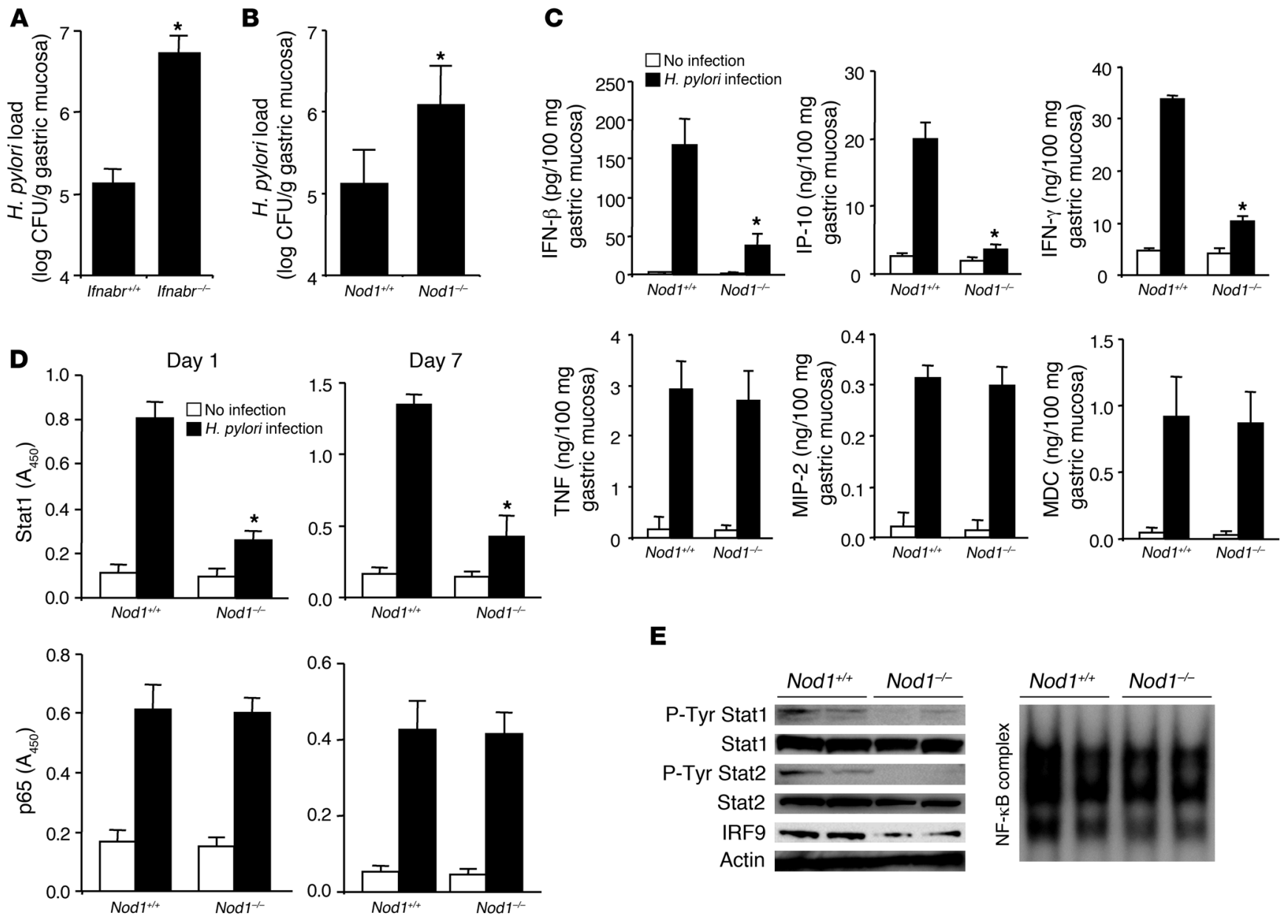

$\mathbf{E}$

Figure 8

NOD1-mediated host defense against $H$. pylori infection of the stomach. (A) Ifnabr+/+ and lfnabr-l- mice were inoculated with cag ${ }^{+} H$. pylori via the oral route. Two weeks after the infection, mice were sacrificed and the stomach was removed to measure the bacterial load. Results are expressed

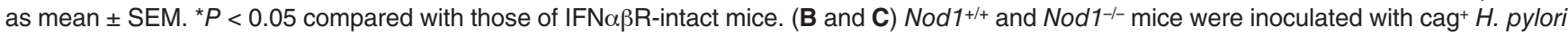
via the oral route. Two weeks after the infection, mice were sacrificed and the stomach was removed. Chemokine and cytokine concentration (measured by ELISA; C) and $H$. pylori concentration (measured by plating; B) were measured in gastric mucosa (normalized for weight of tissue) of the mice 2 weeks after the infection. Data were obtained from 5 mice in each group. Results are expressed as means \pm SEM. ${ }^{*} P<0.05$ compared with NOD1-intact mice. (D and E) Nuclear translocation of Stat1 and p65 in the gastric mucosa 1 day and 1 week after the infection as assessed by Transfactor assay ( $n=5$ in each group; D). Expression of ISGF3 components in whole extracts isolated from the gastric mucosa of the mice as determined by Western blot (left). Activation of NF-кB in nuclear extracts from gastric mucosa was analyzed by EMSA (right). 4 gastric extracts isolated from 2 NOD1-deficient and NOD1-intact mice were subjected to assay (E). Results are expressed as means \pm SEM. ${ }^{*} P<0.05$ compared with those of NOD1-intact mice.

Stat 1 but did not cause significant nuclear translocation of $\mathrm{p} 65$ as measured in the Transfactor assay, whereas TNF stimulation did cause significant translocation. In contrast, as also shown in Figure 6A, primary epithelial cells from IFN $\alpha \beta$ R-deficient mice showed defective production of IFN- $\beta$ and IP-10 but not MIP-2 upon stimulation with NOD1 ligand and, as also shown in Figure $6 \mathrm{~B}$, this reduction of IFN- $\beta$ and IP- 10 was associated with impaired nuclear translocation of Stat 1 in IFN $\alpha \beta$ R-deficient cells. Finally, neutralization of type I IFN signaling by an IFN $\alpha \beta R$ $\mathrm{mAb}$ decreased IP-10 production but had no effect on the production of MIP-2 in primary epithelial cells from wild-type mice (data not shown). These data thus verify with primary intestinal epithelial cells that NOD1 activation results in the production of IFN- $\beta$ and IP-10 through the ISGF3 pathway rather than the
NF- $\kappa B$ pathway. Finally, it should be noted that responses of primary gastric epithelial cells were also studied in relation to in vivo studies of $H$. pylori infection (see below).

We also addressed the role of TBK1, IKKe, and IKK $\beta$ in NOD1induced IFN- $\beta$ production. As shown in Supplemental Figure 11, whereas IFN- $\beta$ production induced by NOD1 ligand was not impaired in IKK $\beta$-deficient MEFs, it was severely impaired in TBK1/IKKe-double-deficient MEFs. Similarly, NOD1-mediated nuclear translocation of Stat 1 was not impaired in IKK $\beta$-deficient MEFs but was severely impaired in TBK1/IKKe-double-deficient MEFs. On the other hand, IFN- $\beta$ induced similar amounts of nuclear translocation of Stat 1 in wild-type, TBK1/IKKe-doubledeficient, and IKK $\beta$-deficient MEFs, whereas TNF induced reduced nuclear translocation of $\mathrm{p} 65$ in IKK $\beta$-deficient MEFs. These data 

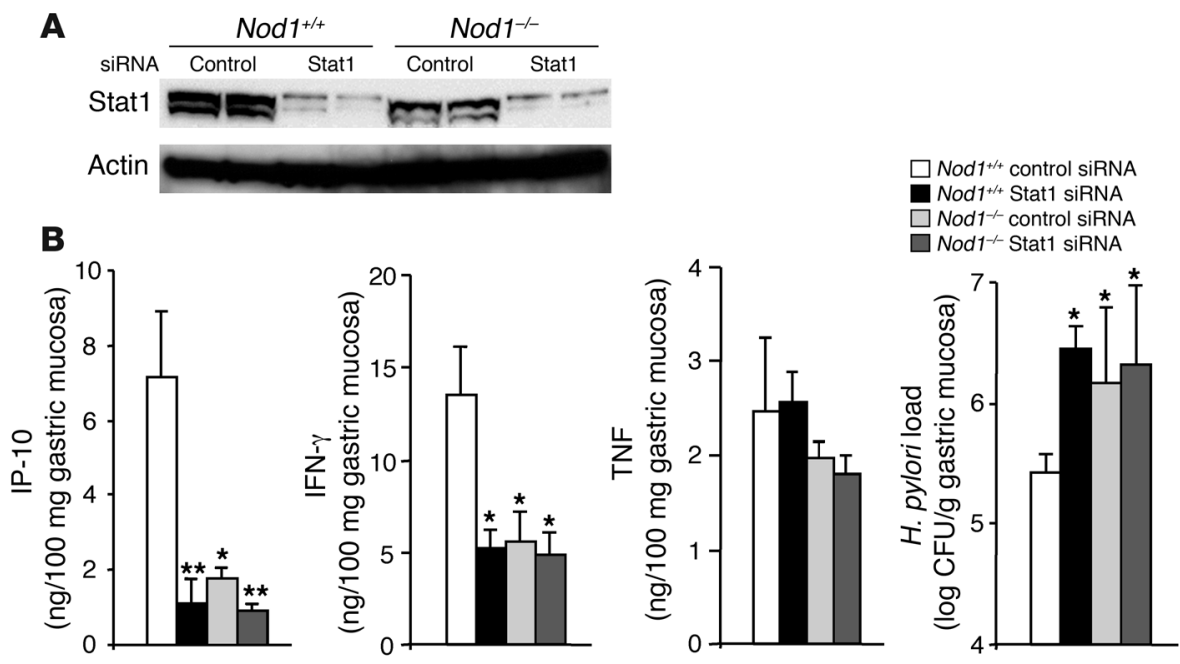

\section{Figure 9}

NOD1-mediated host defense against $H$. pylori depends on activation of Stat1. Nod $1^{+/+}$and $\mathrm{Nod}^{-/-}$mice injected with Stat1 siRNA or control siRNA encapsulated in HVJ-E vector intraperitoneally before infection of $H$. pylori. (A) Expression of total Stat 1 in extracts (isolated from the gastric mucosa) of the mice treated with Stat1 siRNA or control siRNA encapsulated in HVJ-E as determined by Western blotting. 2 gastric extracts from each group were used for the assay. (B) IP-10, IFN- $\gamma$, TNF, and $H$. pylori concentrations (normalized for the weight of tissue in the gastric mucosa). Results are expressed as means \pm SEM. ${ }^{*} P<0.05$; ${ }^{\star \star} P<0.01$ compared with those of NOD1intact mice treated with control siRNA. using MEFs provide additional evidence that NOD1 activation of type I IFN signaling depends on TBK1 and IKKe but not IKK $\beta$.

Activation of ISGF3 and NF- $\mathrm{\kappa} B$ by $H$. pylori infection. In a final series of in vitro studies, we investigated NOD1 ligand activation of the ISGF3 signaling pathway during stimulation of NOD1 by intact H. pylori. To this end, we infected AGS cells with $\mathrm{cag}^{+} H$. pylori strain (TN2GF4), recognizing that the latter release NOD1 ligand into cells via a type IV secretion system $(12,31)$. As shown in Supplemental Figure 12, $H$. pylori infection of the AGS cells led to a massive increase of IFN- $\beta$, IP-10, and IL-8 production accompanied by activation of both Stat 1 and Stat 2 and nuclear translocation of Stat1. However, in contrast to the outcome of NOD1 ligand alone, $H$. pylori infection also led to activation of NF- $\mathrm{KB}$ as assessed by degradation of IкB $\alpha$ and nuclear translocation of p65 and p50. Thus, these data show that $\mathrm{cag}^{+} H$. pylori organisms do indeed activate epithelial cells via the IFN- $\beta$-ISGF3 pathway and in this case

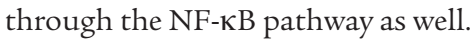

Activation of NF-KB by $H$. pylori does not necessarily contradict our previous findings that NOD1 is a poor activator of NF- $\kappa \mathrm{B}$, since it is possible that such activation does not involve NOD1. To investigate this possibility, we studied $H$. pylori effects on AGS cell responses in the presence of siRNAs specific for NOD1, Stat1, and $\mathrm{p} 65$. As shown in Supplemental Figure 13A, we first showed that the siRNAs used were capable of knocking down their specific target proteins. Then, as shown in Supplemental Figure 13, $B$ and C, we showed that infection of AGS cells in the presence of siRNA specific for NOD1 resulted in impaired nuclear translocation of Stat 1 and production of IFN- $\beta$ and IP-10 upon infection with this organism, while transfection of this siRNA had no effects on nuclear translocation of $\mathrm{p} 65$ or on IL-8 production. In contrast, infection of cells in the presence of siRNA specific for p65 and Stat 1 led to impaired nuclear translocation of these transcription factors and to reduced production of IL- 8 and IFN- $\beta$, respectively. These studies revealed that p65 activation in response to $H$. pylori infection does not in fact depend upon NOD1, which is fully consistent with a previous study by Hirata et al., which showed that $H$. pylori organisms can activate NF- $\kappa \mathrm{B}$ in epithelial cell lines through NOD1-independent mechanisms (32), and with a study by Viala et al., which showed that primary gastric epithelial cells infected with $H$. pylori produce chemokines in the absence of nuclear translocation of NF-кB p65 (12).
NOD1 stimulation in vivo results in IFN- $\beta$ and IP-10 production by nonhematopoietic cells. In further studies we sought to show that NOD1 signaling resulting in concomitant and interrelated production of type I IFN and IP-10 can also be achieved in vivo. Initially, we determined the serum IFN- $\beta$ and IP-10 responses of NOD1-intact and NOD1-deficient mice following systemic (intraperitoneal) administration of NOD1 ligand (FK156) (33) or NOD2 ligand (MDP). As shown in Figure 7A, administration of NOD1 ligand induced a burst of IFN- $\beta$ and IP-10 production, peaking 2 hours after ligand administration in NOD1-intact but not in NOD1-deficient mice. In contrast, such induction of IFN- $\beta$ and IP-10 synthesis was not seen in either type of mouse administered NOD2 ligand. No difference was seen in serum levels of IL-12p40 in mice administered the NOD1 or NOD2 ligand, indicating that the doses of NOD ligands used in this study were sufficient to cause immune responses. These data indicate that systemic NOD1 but not NOD2 activation induces IFN- $\beta$ and IP-10 production.

We next determined whether BM-derived hematopoietic cells were responsible for the above production of IFN- $\beta$ and IP-10 following systemic NOD1 activation. To this end we created BMchimeric mice consisting of irradiated NOD1-intact mice bearing a GFP-expressing transgene under an actin promoter (GFP-Tg mice) (34) or NOD1-deficient mice, both reconstituted with either NOD1-intact or -deficient BM cells. Replacement of BM cells was confirmed by flow cytometry analysis of GFP expression 8 weeks after transplantation. More than $85 \%$ of splenic CD $11 b^{+}$cells were GFP-positive in NOD1-deficient mice treated with an intravenous injection of BM cells from GFP-Tg mice, whereas less than $10 \%$ of splenic CD $11 \mathrm{~b}^{+}$cells were GFP-positive in GFP-Tg mice treated with an intravenous injection of BM cells from NOD1-deficient mice. As shown in Figure 7B, NOD1 activation (by ligand administration as described above) elicited comparable serum levels of IFN- $\beta$ and IP-10 in NOD1-intact (GFP-Tg) mice reconstituted with either NOD1-deficient BM cells or NOD1-intact (GFP-Tg) BM cells. In contrast, NOD1 activation elicited equally low serum levels of IFN- $\beta$ and IP-10 in both NOD1-deficient mice transplanted with NOD1-deficient BM cells or NOD1-intact (GFP-Tg) BM cells. These data show that the type of reconstituting hematopoietic cell was irrelevant to the elicited NOD1 response and therefore the responding cells were nonhematopoietic in origin. It thus becomes clear from the in vivo studies described so far that NOD1 activa- 

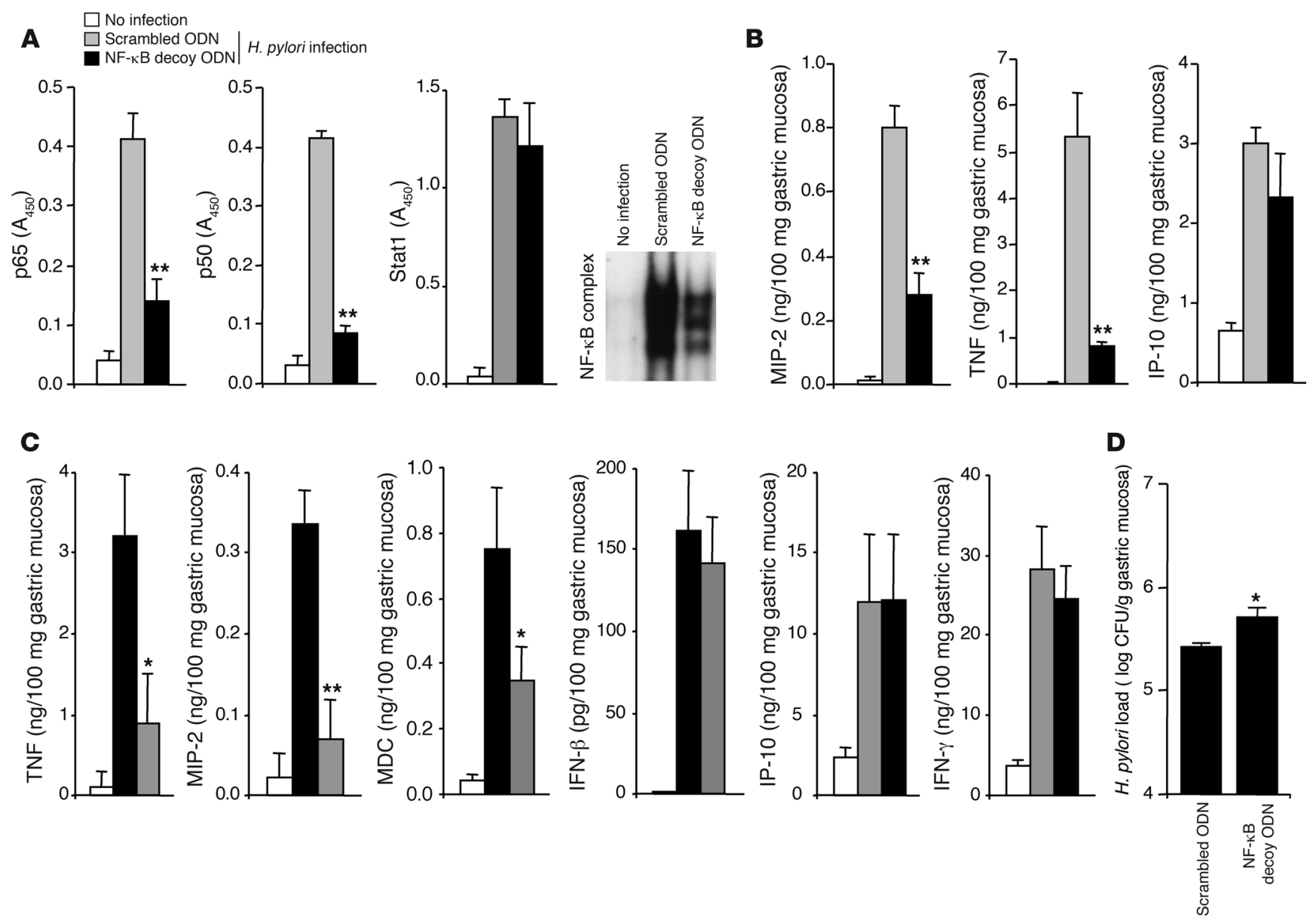

\section{Figure 10}

Role of NF-kB activation in $\mathrm{H}$. pylori infection. C57BL/6 mice were injected with NF-kB decoy ODNs or control scrambled ODNs encapsulated in HVJ-E vector via intraperitoneal route before infection of $H$. pylori. Treatment with decoy ODNs was performed 1 and 2 days before the infection and continued every 3 days during the observation period. (A) Nuclear translocation of p65, p50, and Stat1 in nuclear extracts isolated from the gastric mucosa of mice treated with NF-KB decoy ODNs or control scrambled ODNs 1 day after the infection. Uninfected mice were used as negative controls. Activation of NF-kB in the gastric mucosa was analyzed using EMSA. (B) MIP-2, TNF, and IP-10 concentration in the gastric mucosa 1 day after the infection. Data were obtained from 4 mice in each group. (C and D) IP-10, IFN- $\beta$, IFN- $\gamma$, MIP-2, TNF, and MDC (C) and H. pylori (D) concentrations in the gastric mucosa of the mice 2 weeks after the infection. Data were obtained from 6 mice in each group. Results are expressed as mean \pm SEM. ${ }^{*} P<0.05 ;{ }^{* *} P<0.01$ compared with mice treated with scrambled ODNs.

tion in vivo resulting in production of IP-10 is accompanied by the production of IFN- $\beta$ and that both of these factors are produced by non-hematopoietic host cells such as epithelial cells.

NOD1 mediates host defense against H. pylori through Stat1. To establish the in vivo significance of the NOD1 signaling pathway through type I IFN and ISGF3 to mucosal host defense, we then determined the function of this pathway in gastric mucosal epithelial cells subjected to $H$. pylori infection, i.e., an infection shown previously to be under the control of NOD1 activity (12). In initial studies we measured $H$. pylori bacterial load in IFN $\alpha \beta$ R-deficient and -intact mice as assessed by agar plate culture of serial dilutions of gastric mucosa following infection with cag pathogenicity island-positive H. pylori organisms capable of delivering PGN into gastric epithelial cells via a type IV secretion system (12). As shown in Figure 8A, the bacterial burden in IFN $\alpha \beta$ R-deficient mice was 10 -fold greater than in intact mice, indicating that type I IFN plays a major role in host defense against $H$. pylori infection. In further studies, $H$. pylori bacterial load was measured in NOD1-deficient and NOD1-intact mice, and in this case the effect of the deficiency on bacterial burden and on IFN- $\beta$, IFN- $\gamma$, and IP- 10 production was assessed. As shown in Figure 8B, we found that NOD1 deficiency also gave rise to a greater bacterial burden of about the same magnitude as found with IFN $\alpha \beta$ R deficiency. In addition, as shown in Figure 8C, there was a marked decrease in IFN- $\beta$, IFN- $\gamma$, and IP-10 production in NOD1-deficient mice as compared with NOD1-intact mice. In contrast, there was no difference in the production of MIP-2, TNF, or MDC in the 2 groups of mice.

We then evaluated the activity of ISGF3 signaling pathway in NOD1-deficient and NOD1-intact mice. As shown in Figure 8D, nuclear translocation of Stat1, an ISGF component, was markedly enhanced in the gastric mucosa of NOD1-intact mice 1 or 7 days after infection with $H$. pylori, whereas such translocation was reduced in the mucosa of NOD1-deficient mice. Consistent with this, as shown in Figure 8E, phosphorylation of Stat 1 and Stat2 as well as the expression of IRF9 were greatly decreased in gastric mucosal extracts of NOD1-deficient mice as compared with those 
of NOD1-intact mice. However, as shown in Figure 8, D and E, there was no marked difference in NF-KB activation in NOD1-intact and NOD1-deficient mice as evaluated by EMSA and the Transfactor assay. It should be noted that reduced Stat 1 activation as well as comparable NF- $\kappa \mathrm{B}$ activation was seen in the gastric mucosa of NOD1-deficient mice both at the early and late phases of infection. Thus, reduced IFN $-\beta$ responses associated with increased bacterial loads 2 weeks after the infection were not due to a reduction of IFN- $\gamma$ production by immune cells that had been recruited to the gastric mucosa by NF-кB-dependent chemokines released during the initial phase of infection. Taken together, these results demonstrate that the inability of NOD1-deficient mice to control $H$. pylori infection was in fact associated with evidence of decreased ISGF3 signaling as well as decreased production of IFN- $\beta$, IFN- $\gamma$, and IP-10 rather than a reduced ability to activate NF- $\mathrm{KB}$.

Taking the analysis a step further, we next asked whether the above association between NOD1-mediated ISGF3 signaling and host defense against $H$. pylori were causally related. To test this possibility, we evaluated $H$. pylori infection in NOD1-intact mice whose ISGF3 signaling was impaired by in vivo administration of siRNA targeting Stat1. As shown in Figure 9A, intraperitoneal administration of siRNA specific for Stat1, encapsulated in a viral envelope (derived from the hemagglutinating virus of Japan [HVJ-E]; see Methods) (35) to facilitate siRNA transfection in vivo, did in fact lead to very substantial downregulation of Stat 1 expression in gastric extracts of treated mice. With this knowledge in hand, we then assessed Th 1 chemokine and cytokine production and H. pylori load in H. pylori-infected NOD1-intact mice and NOD1deficient mice administered Stat 1 siRNA or control siRNA. As shown in Figure 9B, IFN- $\gamma$ and IP-10 production were decreased in gastric extracts of NOD1-intact mice administered Stat 1 siRNA. In addition, $H$. pylori load was increased in NOD1-intact mice administered Stat 1 siRNA. As expected, Stat 1 siRNA treatment did not change the bacterial load and IP-10 production in NOD1-deficient mice. Taken together, these data support the view that mucosal host defense against $H$. pylori is mediated at least in part by NOD 1 acting through the ISGF3 signaling pathway.

In a final series of experiments, we assessed the role of NF-кB activation in $H$. pylori infection. In this study, C57BL/ 6 mice were administered NF- $\mathrm{KB}$ decoy oligodeoxynucleotides (ODNs) or control scrambled ODNs in an HVJ-E vector by intraperitoneal injection, a treatment shown previously to inhibit the canonical and noncanonical NF-KB pathways (36). The mice treated in this way were then subjected to H. pylori infection. As shown in Figure 10A, NF- $\kappa \mathrm{B}$ activation assessed by EMSA and Transfactor assay was greatly inhibited in mice administered NF- $\kappa$ B decoy ODNs, whereas in contrast, Stat 1 activation was not impaired by such treatment. Furthermore, as shown in Figure 10B, 1 day after H. pylori infection, such inhibition of NF- $\kappa \mathrm{B}$ activation was accompanied by a marked decrease in the production of the NF- $\kappa \mathrm{B}$-dependent chemokine MIP-2 and cytokine TNF, but not IP-10, in the gastric mucosa. As shown in Figure 10C, even 2 weeks after infection there was persistent inhibition of NF-кB-dependent chemokines (MIP-2 and $\mathrm{MDC}$ ) and cytokine (TNF) in the gastric mucosa, whereas production of IFN- $\beta$, IFN- $\gamma$, or IP-10 was not inhibited by NF-кB decoy treatment. Thus, blockade of NF- $\kappa \mathrm{B}$ activation at the early phase of infection did not alter production of IFN-related responses at the late phase of infection. Finally, as shown in Figure 10D, although a significant increase of the $H$. pylori load was seen in mice treated with NF-кB decoy ODNs $(P=0.023)$, the degree of increase was much smaller compared with the Stat1 siRNA study (Figure 9B). Based on these results, we determined that although NF- $\mathrm{KB}$ activation independent of NOD1 signaling is involved in host defense against $H$. pylori, it is the NOD1-mediated ISGF3 signaling that generates protective Th1 responses to this organism.

Taken together, these in vivo studies provide convincing verification that the dependence of NOD1 induction of IP-10 on the production of the type I IFN/ISGF3 signaling pathway shown above in in vitro studies can also be obtained in vivo.

\section{Discussion}

The studies performed here provide important new insights into the mechanism of NOD1 signaling and the role of NOD1 in protection against infection at mucosal surfaces. With respect to signaling, we show that NOD1 activated by purified NOD1 ligand (iE-DAP) induces chemokine production via a pathway primarily induced by type I IFN, namely the activation of a heterotrimeric transcription factor complex composed of Stat1, Stat2, and IRF9 known as ISGF3. Furthermore, we show that this pathway is initiated by an interaction between RICK and TRAF3 that leads to activation of the TRAF3 downstream components TBK1 and IKKE and, in turn, to the activation of IRF7 and the production of IFN- $\beta$. The latter then activates the aforementioned ISGF3 pathway. With respect to function, we show that NOD1 activation leads to induction of chemokines associated with the Th1 response (IP-10 and I-TAC) as well as IFN- $\beta$, and that in vivo inhibition of the ISGF3 pathway via administration of Stat 1 siRNA greatly impairs host defense against $H$. pylori infection of the gastric mucosa. In addition, loss of IFN- $\beta$ signaling resulting from IFN $\alpha \beta$ R deficiency has a similar effect. Thus, as shown in the diagram depicted in Supplemental Figure 14, these studies establish the somewhat unexpected finding that NOD1 signaling utilizes the type I IFN-induced ISGF3 pathway to enable host defense.

The findings summarized above, which establish that NOD1 signaling in epithelial cells is mainly channeled through the type I IFN/ISGF3 pathway, were accompanied by a complementary set of findings showing that NOD1 signaling is largely independent of NF- $\mathrm{KB}$ and MAPK activation. These findings are seemingly at odds with a number of previously published studies that support the view that NOD1 signaling does involve such activation $(15,17,37$, 38). However, virtually without exception these prior studies evaluated NOD1 signaling in overexpression systems consisting of cells (usually non-epithelial cells such as HEK293 cells) transfected with NOD1 expression vectors and/or target reporter constructs rather than in physiologic cells expressing endogenous NOD1 and NOD1 targets. As might be expected, such overexpression studies are subject to false-positive outcomes and, even if this is not the case, may not apply to all types of cells. This is illustrated by the fact that while in our initial overexpression studies NOD1 activation seemingly led to NF- $\kappa$ B activation (see Supplemental Figure 1), a massive amount of subsequent data derived from both in vitro and in vivo studies not involving overexpression told a very different story. Thus, in our in vitro studies we found first that specific inhibitors of ERK and JNK activation had no effect and an inhibitor of NF- $\mathrm{KB}$ had only a marginal effect on NOD1-mediated chemokine production, whereas an inhibitor of RICK clearly blocked such production. Second, we found that phosphorylation of p38 MAPK or JNK was not observed in cells stimulated with NOD1 ligand, and in studies of nuclear translocation of the NF- $\mathrm{KB}$ subunits, a sensitive mobility shift analysis was weakly positive and a Transfactor bind- 
ing assay was negative. In contrast, NOD1 stimulation led to robust activation and translocation of all 3 components of ISGF3 (Stat1, Stat2, and IRF-9). Third, we showed that transfection of cells with siRNA specific for RICK, Stat1, or Stat2 led to downregulation of chemokine production, whereas transfection of siRNA specific for p 65 or p38 MAPK had little or no effect on such production. In addition, siRNA specific for TBK1 and IKKE also downregulated chemokine production, as did blockade of type I IFN signaling by anti-IFN $\alpha \beta$ R. Fourth, we found that while primary intestinal epithelial cells produced a significant amount of IFN- $\beta$ and IP-10 via type I IFN signaling upon stimulation with NOD1 ligand, primary cells lacking IFN $\alpha \beta$ R failed to produce IFN- $\beta$ and IP-10. Fifth, we determined that while activation of NOD1 led to defective production of IFN- $\beta$ and IP-10 in TBK1/IKKE-double-deficient MEFs, such activation led to greatly induced production of these products in IKK $\beta$-deficient MEFs. Finally, these data obtained with the use of cell line epithelial cells were corroborated by key studies of freshly isolated epithelial cells.

Extensive in vivo studies of NOD1 signaling, including studies of such signaling in relation to $H$. pylori infection, provided important verification of the above in vitro studies. Thus, initial studies showed that stimulation of mice with NOD1 ligand induced a robust IFN- $\beta$ response along with an IP-10 response arising from nonhematopoietic cells. Further studies showed that the increased susceptibility of NOD1-deficient mice to $H$. pylori infection was associated with a decreased ability to produce IFN- $\beta$ and IP-10, both factors dependent on the ISGF3 signaling pathway and, in fact, infected gastric tissue manifested evidence of decreased activation of components of this pathway. Importantly, the decreased cytokine/chemokine response of $H$. pylori-infected NOD1-deficient mice was accompanied by a level of NF- $\mathrm{\kappa B}$ activation equivalent to that of NOD1-intact mice, and indeed the NOD1-deficient mice produced ample amounts of NF- $\mathrm{KB}$-dependent chemokines and cytokines. These results were therefore parallel to those obtained with $H$. pylori-infected cells in vitro, where it was found in our own studies as well as previous studies of Hirata et al. that NF- $\kappa \mathrm{B}$ activation by $H$. pylori is independent of NOD1 (32).

The above in vivo data were then augmented by studies addressing the causal relation between ISGF3 signaling and H. pylori infection, in which it was shown that administration of Stat1-specific siRNA inhibited upregulation of $1 \mathrm{P}-10$ and IFN- $\gamma$ production in response to $H$. pylori infection and led to a decreased ability to control such infection on the gastric mucosal surface. By contrast, downregulation of NF- $\mathrm{KB}$ in vivo by administration of NF- $\mathrm{KB}$ decoy ODN did not inhibit the upregulation of IP-10 or IFN- $\beta$ production in response to $H$. pylori infection. In addition, it led to only a minor decrease in the ability of the treated mouse to control such infection that was not necessarily related to effects on NOD1 signaling since the decoy ODN also downregulated TNF production. Since the NF-кB decoy ODN has previously been shown to

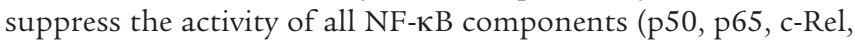
p52, and RelB), this study also rules out the possibility that NOD1 signals through a noncanonical NF-кB pathway (36). Overall, these in vivo data strongly support the conclusion that NOD1 induction of chemokines in gastrointestinal epithelial cells support the conclusion that NOD1 signaling and chemokine induction in epithelial cells is at best only marginally dependent on the NF- $\mathrm{KB}$ and MAPK pathway and instead is heavily dependent on the ISGF3-IFN- $\beta$ pathway. This conclusion is not undermined by the fact that NOD1 stimulation of epithelial cells induces IL-8 because type I IFN has previously been shown to greatly enhance production of this chemokine (39).

Of interest, evidence supporting this view of NOD1 signaling has been reported by 2 groups. In one study it was shown with microarray technology that an epithelial cell line stimulated by

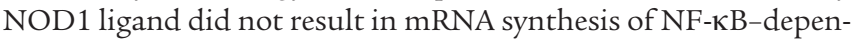
dent inflammatory cytokines such as TNF and IL-1 (9), while in another study it was found that activation of primary gastric epithelial cells with $H$. pylori, resulted in the production of chemokines in the absence of nuclear translocation of NF-кB p65 (12).

One important caveat to the conclusion that NOD1 stimulation does not lead to substantial NF-KB activation relates to previous studies showing that this signaling pathway may be operative in nonintestinal epithelial cells such as mesothelial cells or renal epithelial cells (40-43). This possibility is also supported by our finding that lack of NOD1 signaling may lead to diminished synthesis of NF-KB-dependent cytokines in dendritic cells: IL-12p40 synthesis is diminished in NOD1-deficient mice upon in vivo administration of ligand, and IL- 6 synthesis is decreased in NOD1-deficient BMDCs upon in vitro ligand stimulation. Thus, at least in certain APCs, NOD1 signaling may indeed involve NF- $\kappa$ B activation. It should also be noted that NOD1 signaling of THP1 cells (a monocytic cell line) does not induce IP-10 production and, in addition, such signaling is not accompanied by interaction between RICK and TRAF3, suggesting that even in monocytic cells, type I IFN and the ISGF3 pathway is necessary for chemokine induction.

A key finding in this study was that NOD1 activation results in a form of RICK that binds to TRAF3 and thereby initiates signaling through TBK1/IKKE and IRF7 to induce IFN- $\beta$. The interaction of NOD1-activated RICK with TRAF3 (rather than with TRAF6) results in activation of a TRAF that has been shown to profoundly suppress both the canonical and noncanonical NF- $\mathrm{KB}$ pathway, thus providing an explanation for why the latter pathway is not utilized in NOD1 activation (23). It should be noted, however, that our findings do not answer the question of why NOD1-activated RICK, unlike NOD2-activated RICK, interacts preferentially with TRAF3 and not with TRAF6. One mechanism we considered was that NOD1 induces RICK kinase function, which then phosphorylates TRAF3. However, we found that this cannot be the case, since mutations of RICK leading to loss of all kinase function do not impair the ability of RICK to mediate NOD1 ligand-induced IP-10 synthesis in HT-29 cells (our unpublished observations). This negative finding, however, allowed us to rule out that NOD1-activated RICK directly activates ISGF3 by phosphorylating Stat 1 and Stat2 (rather than acting via TRAF3 and IFN- $\beta$ ). Finally, while NOD1 induction of chemokines via an ISGF3-mediated pathway may seem unusual, the use of this pathway (and not the NF-KB pathway) has previously been demonstrated with respect to LPS signaling (41). In the latter case, it was shown that LPS induces only low amounts of IP-10 (and certain other chemokines) in the absence of type I IFN induction. Presumably, LPS enters the type I IFN/ISGF3 system via TRIF activation of TRAF3. These studies along with the present studies show that ISGF3 transactivation of the IP-10 promoter at an ISRE site is sufficient for robust IP-10 transcription even though

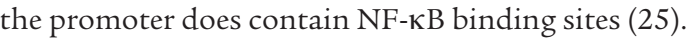

The dominance of type I IFN pathway over the NF-KB pathway in the induction of host defense factors by NOD1 in mucosal epithelial cells may be advantageous to the organism because only this pathway results in the concomitant induction of type I IFN, which 
is itself a host defense factor at mucosal surfaces. Indeed, we have shown that mice deficient in the IFN $\alpha \beta R$, which have epithelial cells that cannot be signaled by type I IFN, exhibit 10-fold greater $H$. pylori burden compared with wild-type mice. An additional salutary effect of type I IFN production is inherent in the fact that this cytokine has been shown to enhance epithelial cell barrier function and therefore may act to prevent entry of invasive organisms into the lamina propria (40). Finally, it should be noted that NOD1induced type I IFN induction may be greatly enhanced by concomitant TLR signaling. This is suggested by the fact that stimulation of HT-29 cells with both LPS and NOD1 ligand leads to synergistic effects of type I IFN production (data not shown), possibly because LPS also induces activation of IRF3, a factor that acts in concert with IRF7 in the induction of type I IFN production (44).

$H$. pylori infection of the gastric mucosa is an important risk factor for peptic ulcer disease and gastric cancer (45). An adaptive immune response is inherent in the fact that persistent colonization of the mucosa with this organism leads to a strong Th1 response $(46,47)$ that is accompanied by a reduction in the gastric bacterial load (48). Innate immune responses to this organism are also likely to play a role in host defense, both directly and indirectly through the facilitation of the adaptive Th1 response. While a major role for TLR4 and TLR5 in this innate response seems to be excluded by both the fact that $H$. pylori LPS has weak activity compared with LPS from E. coli or Salmonella typhimurium, and the fact that $H$. pylori flagellin is not inflammatory $(49,50)$, TLR2 may be involved in the innate response, since the neutrophil-activating protein of $H$. pylori induces IL-12 and IL-23 secretion via activation of this TLR (51). Previous studies by Viala et al. (12) as well as those described here provide further support for the notion that innate immunity, in this case in the form of NOD1 activity, is involved in host defense against $H$. pylori infection. This follows from studies conducted previously and confirmed here showing that NOD1deficient mice exhibit increased susceptibility to infection. In addition, in the present study, activation of NOD1 leads to remarkably high production of chemokines that are critically important to the trafficking of Th1 cells to sites of inflammation and infection in the gut and elsewhere (52). The fact that IP-10 expression has been observed in human gastric tissue infected with $H$. pylori fits well with this view (53). Based on the results shown here, we propose that the generation of Th1 responses in H. pylori infection occurs as follows: $H$. pylori activates NOD1 in gastric epithelial cells through type IV secretion system, which then gives rise to IP-10 production via ISGF3 signaling and initial attraction of Th1 cells to the site of infection. While at first IP-10 production is relatively low in the absence of IFN- $\gamma$-induced upregulation of NOD1 expression, it increases dramatically with the influx of Th1 cells and the attendant increase in IFN- $\gamma$ production. On a separate track, the epithelial cells begin to produce type I IFN, which leads to Th1 differentiation and further augmentation of the ongoing Th1 inflammation (54). Finally, it should be pointed out that these outcomes of NOD1 activation are relevant to other infections at the mucosa in addition to that caused by $H$. pylori, including infection caused by Pseudomonas aeruginosa and Chlamydophila pneumoniae (12, 55, 56). We therefore look forward to further work exploring whether NOD1 plays a similar role in host defense against these infections as it does against $H$. pylori.

In conclusion, we have identified what we believe is a novel signaling pathway mediated by NOD1 in gastrointestinal epithelial cells. This pathway is dependent upon induction of type I
IFN and activation of the ISGF3 complex. We have thus mapped out a new dimension of NOD1 activity that enlarges its role in mucosal host defense.

\section{Methods}

Animals. NOD1-deficient mice with C57BL/6 background were provided by Millennium Pharmaceuticals and reared in the animal facility of the NIH. Wild-type C57BL/6 (NOD1-intact) mice were obtained from The Jackson Laboratory. IFN $\alpha \beta R$-deficient mice were gifts from H. Young (National Cancer Institute). Animal use was approved by the National Institute of Allergy and Infectious Diseases Animal Care and Use Committee and adhered to NIH Animal Care Guidelines.

Ligands and plasmids. iE-DAP was obtained from Peptide Institute and was shown to be more than $99 \%$ pure by HPLC analysis. FK156 was provided by Astellas Pharmaceuticals (33). MDP and iE-DAP (commercially available) were obtained from Sigma-Aldrich and Invivogen, respectively. pUNO plasmid expressing human TRAF3 cDNA was obtained from Invivogen. Human RICK-expressing plasmid was obtained from Invivogen, and the V5 tag peptide sequence was added at the $3^{\prime}$ end of RICK cDNA using the KOD-plus Mutagenesis kit (Toyobo).

Cells and stimulation. HT-29 cells and AGS cells were purchased from ATCC. These cells $\left(1 \times 10^{6} / \mathrm{ml}\right.$ or $\left.5 \times 10^{5} / \mathrm{ml}\right)$ were untreated or were prestimulated with recombinant human IFN- $\gamma(10 \mathrm{ng} / \mathrm{ml}$ or $100 \mathrm{ng} / \mathrm{ml}$; Peprotec) or TNF (10 ng/ml or $100 \mathrm{ng} / \mathrm{ml}$; Peprotec) for 24 hours, followed by overnight stimulation with iE-DAP $(1,10$, or $100 \mu \mathrm{g} / \mathrm{ml})$ or $\operatorname{MDP}(1,10$, or $100 \mu \mathrm{g} / \mathrm{ml})$. Cultured supernatants were assayed for the levels of IP-10 (R\&D Systems), I-TAC (R\&D Systems), IL-8 (R\&D Systems), MDC (R\&D Systems), and IFN- $\beta$ (Biosource) using ELISA kits. BMDCs $\left(10^{6} / \mathrm{ml}\right)$ were generated as described previously (35) and stimulated with $10 \mu \mathrm{g} / \mathrm{ml}$ of iE-DAP or MDP for 24 hours. Cultured supernatants were analyzed for IL-6 production with an ELISA kit from eBioscience. Primary epithelial cells from the small intestine were isolated as described previously $(57,58)$. Briefly, dissected short segments of the small intestine from 5 mice were stirred at $37^{\circ} \mathrm{C}$ in prewarmed RPMI- 1640 containing L-glutamine, penicillin, streptomycin, and gentamicin with $2 \%$ calf serum for 10 minutes, followed by vigorous shaking for 15 seconds. The resulting supernatants were separated on a discontinuous Percoll density gradient (Pharmacia). The cells that layered between the $40 \%$ and $25 \%$ interface were collected as epithelial cells. Cells $\left(10^{6} / \mathrm{ml}\right)$ were stimulated with $100 \mu \mathrm{g} / \mathrm{ml}$ of iE-DAP for 24 hours. Cultured supernatants were analyzed for production of IP-10, IFN- $\beta$, and MIP-2 using ELISA kits from R\&D systems. Wild-

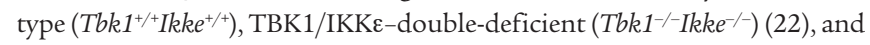
IKK $\beta$-deficient $\left(\mathrm{Ikkb}^{--}\right) \mathrm{MEFs}\left(10^{6} / \mathrm{ml}\right)(19)$ were stimulated with iE-DAP

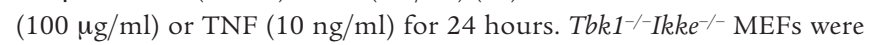
provided by K. Ishii and S. Akira (Osaka University, Osaka, Japan). Ikkb-/MEFs were provided by S. Yamaoka (Tokyo Medical and Dental University, Tokyo, Japan) and M. Pasparakis (University of Cologne, Cologne, Italy). Cultured supernatants were subjected to IFN- $\beta$ and IP-10 assays.

Inbibitors for MAPK and NF-КB. HT-29 cells were either not stimulated or were pre-stimulated with $100 \mathrm{ng} / \mathrm{ml}$ of IFN- $\gamma$ for 24 hours and then incubated with SB203580 (p38 or RICK inhibitor), PD98059 (ERK inhibitor), SP600125 (JNK inhibitor), or BAY11-7082 (NF-kB inhibitor) for 1 hour, followed by overnight stimulation with iE-DAP (10 or $100 \mu \mathrm{g} / \mathrm{ml})$. In some experiments, cells were pre-incubated with $20 \mu \mathrm{M}$ of these inhibitors and then stimulated with TNF $(50 \mathrm{ng} / \mathrm{ml})$.

Luciferase assay. NF- $\mathrm{kB}$ luciferase assay was done as described previously (13). Briefly, HT-29 cells $\left(1.5 \times 10^{5} / \mathrm{ml}\right)$ were transiently transfected with the reporter plasmid pNF- $\mathrm{\kappa B}-$ Luc containing $4 \mathrm{\kappa B}$ binding sites (Clontech) and PSV- $\beta$-galactosidase vector (Promega), together with a plasmid expressing TLR or NOD by Trans-ITLT1 reagent (Mirus). In the case 
of TLR4-mediated NF-KB activation, an MD2-expressing plasmid was cotransfected with the TLR4-expressing plasmid. In some experiments, TRAF3 siRNA (Santa Cruz Biotechnology Inc.; $50 \mathrm{nM}$ ) was transfected. After overnight incubation in serum-free medium, cells were stimulated with iE-DAP or positive-control TLR ligands for 5 hours, and then cell lysates were analyzed for luciferase activity (Promega) and galactosidase activity (Applied Biosystems), the latter for normalization.

Immunoblot analyses. HT-29 cells were either not stimulated or were prestimulated with $100 \mathrm{ng} / \mathrm{ml}$ of IFN- $\gamma$ for 24 hours and then restimulated with 10 or $100 \mu \mathrm{g} / \mathrm{ml}$ of iE-DAP. In some experiments, cells were stimulated with $50 \mathrm{ng} / \mathrm{ml}$ of TNF or $1,000 \mathrm{U} / \mathrm{ml}$ of IFN- $\beta$ (R\&D systems) to obtain positive control samples. At the indicated time points, cells were lysed in lysis buffer (1\% NP-40, $150 \mathrm{mM} \mathrm{NaCl}, 20 \mathrm{mM}$ Tris, pH 7.5, 2 mM EDTA) supplemented with protease inhibitor cocktails (Roche Molecular Biochemicals) for 30 minutes on ice, then centrifuged at $12,000 \mathrm{~g}$ for 30 minutes at $4^{\circ} \mathrm{C}$, at which point the lysis supernatants were collected. The lysates were mixed with SDS sample buffer, incubated at $70^{\circ} \mathrm{C}$ for 10 minutes, run in NUPAGE Novex Bis-Tris Gels ( $25 \mu \mathrm{g} /$ well; Invitrogen), and transferred to a nitrocellulose membrane (Amersham Pharmacia Biotech). The blotted membrane was blocked with $5 \%$ skim milk/TBS/0.1\% Tween-20, washed, and incubated with primary antibody, followed by incubation with HRP-conjugated antigoat IgG or anti-rabbit IgG (Zymed). The primary antibodies used in this study were as follows: anti-NOD1 (Alexis Biochemicals), actin, IRF3, IRF7, IRF9, USF-2 (Santa Cruz Biotechnology Inc.), p-p38, total p38, p-ERK,

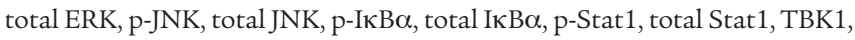
IKKe (Cell Signaling), p-Stat2 (Upstate), total Stat2 (Active motif), RICK (Cayman), TRAF3 (abcam). To detect NOD2 expression, cells were first immunoprecipitated with monoclonal NOD2 antibody (eBioscience), followed by immunoblotting with polyclonal NOD2 antibody (Novus) using a Trueblot kit (eBioscience). Whole lysates from HT-29 cells transfected with NOD1 or NOD2 cDNA were used as a positive control. The membrane was developed by Supersignal West Pico Chemiluminescent Substrate (Pierce Chemical Co.) and exposed to an $\mathrm{x}$-ray film.

Immunoprecipitation. HEK293 cells (ATCC) $\left(5 \times 10^{5} / \mathrm{ml}\right)$ were transfected with $2 \mu \mathrm{g}$ of V5-tagged human RICK vector together with $2 \mu \mathrm{g}$ of human TRAF3 by Trans IT LT1 (Mirus). Whole cell lysates were prepared 48 hours after the transfection and were incubated with anti-V5 conjugated beads (Bethyl Laboratories) overnight. In some experiments, whole cell lysates were prepared from HT-29 cells $\left(10^{6} / \mathrm{ml}\right)$ or THP1 cells $\left(10^{6} / \mathrm{ml}\right)$ stimulated with iE-DAP or MDP for 1 hour. These lysates were incubated with anti-RICK (Santa Cruz Biotechnology Inc.) or anti-TRAF3 (Abcam) and protein A/G plus agarose (Santa Cruz Biotechnology Inc.), as described previously (35).

$N F-\mathrm{K} B$ activation assay and EMSAs. HT-29 cells were either not stimulated or pre-stimulated with $100 \mathrm{ng} / \mathrm{ml}$ of IFN- $\gamma$ for 24 hours and then restimulated with 10 or $100 \mu \mathrm{g} / \mathrm{ml}$ of $\mathrm{iE}-\mathrm{DAP}$. At the indicated time points, nuclear extracts were prepared using an extraction kit (Clontech) and binding activity of nuclear extract to NF-kB subunit, p50, p65, p52, and RelB was measured using a Mercury Transfactor kit (Clontech) (13). Nuclear extracts isolated from HT-29 cells stimulated with TNF $(50 \mathrm{ng} / \mathrm{ml})$ for 1 hour were used as positive controls for the p65 and p50 assay. Nuclear extracts from Raji cells were used as positive controls for p52 and RelB assay. Nuclear extract $(30 \mu \mathrm{g})$ was applied to each well coated with NF- $\mathrm{KB}$ consensus oligonucleotides and then incubated with rabbit anti-p50, anti-p65, anti-p52, and anti-RelB, followed by HRP-labeled anti-rabbit IgG. Semiquantitative analysis of IRF7 and Stat 1 expression was done using a TransAM IRF kit or Stat kit (Active Motif). Nuclear extract $(20 \mu \mathrm{g})$ was applied to each well, which was coated with IRF or Stat consensus oligonucleotides, and then incubated with rabbit anti-IRF7 or anti-Stat 1 antibody, followed by HRP-labeled anti-rabbit IgG. Nuclear extracts isolated from HT-29 cells stimulated with IFN- $\beta$ for 1 hour were used as positive controls. EMSA for the analysis of activation of NF-KB or ISGF3 were performed as previously described (13). Binding reactions containing $5 \mu \mathrm{g}$ nuclear extracts and 2 ng end-labeled ISRE or IFN- $\gamma$-activated site binding consensus oligonucleotides (59) were performed for 20 minutes at room temperature in $15 \mu \mathrm{l}$ binding buffer ( $20 \mathrm{mM}$ Hepes, $\mathrm{pH} 7.9,30 \mathrm{mM} \mathrm{KCl}, 4 \mathrm{mM} \mathrm{MgCl}_{2}$, $0.1 \mathrm{mM}$ EDTA, $0.8 \mathrm{mM} \mathrm{NaPi}, 20 \%$ glycerol, $4 \mathrm{mM}$ spermidine, and $3 \mathrm{mg}$ poly dI-dC). For supershift analysis, anti-Stat1, anti-Stat2, or anti-IRF9 antibodies (Santa Cruz Biotechnology Inc.) were used.

siRNA assays. siRNAs specific to p38, p65, NOD1, Stat1 (Santa Cruz Biotechnology Inc.), RICK, TBK1, and IKKe (Dharmacon) were used. siRNA specific to GFP was used as a control. HT-29 cells were transfected with 20 or $100 \mathrm{nM}$ of these siRNAs with Trans-siQuest reagent (Mirus) and then stimulated with $100 \mathrm{ng} / \mathrm{ml}$ of IFN- $\gamma$ and $10 \mu \mathrm{g} / \mathrm{ml}$ of iE-DAP. Cultured supernatants were analyzed for chemokine production by ELISA kits. For neutralization of ISGF3-signaling pathways, vectors expressing Stat 1 or Stat 2 siRNA (Panomics) were used. HT-29 cells $\left(2.5 \times 10^{5} /\right.$ well in a 12-well plate) were transfected with $125 \mathrm{ng}$ of control vector, Stat 1 siRNA-expressing vector, or Stat 2 siRNA-expressing vector by Trans-ITLT1 reagent (Mirus) and then stimulated with $100 \mathrm{ng} / \mathrm{ml}$ of IFN- $\gamma$ and either 10 or $100 \mu \mathrm{g} / \mathrm{ml}$ of iE-DAP. Cultured supernatants were then analyzed for chemokine production as described above.

In vivo injection study. NOD1-deficient mice and NOD1-intact mice (12) were given an intraperitoneal injection of FK156 (NOD1 ligand, $200 \mu \mathrm{g}$ ) or $\operatorname{MDP}(200 \mu \mathrm{g})$. At the indicated time points, sera were prepared from these mice to measure the levels of IP-10, IFN- $\beta$, and IL-12p40 using ELISA kits from R\&D Systems. BM-chimeric mice were created by using GFP-Tg mice and NOD1-deficient mice as previously described (33). Recipient mice were irradiated (10 Gy), followed by intravenous injection of $2 \times 10^{6} \mathrm{BM}$ cells. At 8 weeks after BM transplantation, the mice were given an intraperitoneal injection of FK156 (NOD1 ligand, $200 \mu \mathrm{g}$ ). Sera were prepared from these mice 2 hours after the injection to measure the level of IP-10 and IFN- $\beta$.

In vitro $H$. pylori infection study. AGS cells $\left(5 \times 10^{5} / \mathrm{ml}\right)$ were stimulated with the $\mathrm{cag}^{+} H$. pylori strain (TN2GF4) as previously described (31). Cells were cultured for 24 hours, and cultured supernatants were analyzed for the production of IFN- $\beta$, IP-10, and IL-8. Whole cell extracts and nuclear extracts were isolated and subjected to immunoblotting and Transfactor assay. In some experiments, AGS cells $\left(2.5 \times 10^{5} / \mathrm{ml}\right.$ in 12 -well plates) were transfected with NOD1 siRNA, p65 siRNA, Stat 1 siRNA, or control siRNA (20 nM each), and after 48 hours, cells were cultured for a further 24 hours with or without $H$. pylori as previously described (31).

In vivo $H$. pylori infection study. NOD1-deficient mice and NOD1-intact mice (12) were maintained under specific pathogen-free conditions in the animal facilities of NIH. Male and female mice 6-8 weeks old were used. NOD1-deficient mice and NOD1-intact mice were administered $\mathrm{a} \mathrm{cag}^{+}$ H. pylori strain (TN2GF4) via the oral route $\left(2.45 \times 10^{9} \mathrm{CFU}\right)$. At 2 weeks after the infection, mice were sacrificed and the stomach was removed from each mouse. The stomach was opened along the greater curvature and weighed. Half was used for protein isolation, and the other half was used for the quantitative culture of $H$. pylori as described previously (60). In some experiments, siRNA targeting Stat 1 obtained from Dharmacon was administered in HVJ-E vector during the period of infection. Sequences of the administered siRNAs were as follows: control siRNA, 5'-UAAGGCUAUGAAGAGAUACUU-3'; Stat 1 siRNA, 5'-AUUCCAUCGAGCUCACUCAdTdT-3' (61). siRNAs were encapsulated in HVJ-E vector as previously described (13). Control siRNA or Stat 1 siRNA $(100 \mu \mathrm{g})$ was administered to mice intraperitoneally starting the day before $H$. pylori infection and then every 3 days during the experimental period. To inhibit NF- $\mathrm{KB}$ activation, C57BL/ 6 mice were treated with NF-KB decoy ODNs or control scrambled ODNs encapsuled with HVJ-E vector followed by oral administration of

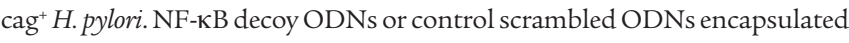


with HVJ-E vector were prepared as described previously (36). Treatment with NF-KB decoy ODNs or control scrambled ODNs was performed 1 and 2 days before the $H$. pylori infection and continued every 3 days during the observation period. Whole-protein extracts and nuclear extracts from gastric mucosa were isolated using a total protein extraction kit (Chemicon) and nuclear extraction kit (Active Motif), respectively. Concentrations of IP-10, IFN- $\beta$, MDC, and MIP-2 were determined using ELISA kits from R\&D Systems; concentrations of IFN- $\gamma$ and TNF were determined using ELISA kits from BD Biosciences - Pharmingen.

Statistics. Student's $t$ test (2 tailed) was used to evaluate the significance of the differences. Statistical analysis was performed with the StatView v.4.5 program (Abacus Concepts). A value of $P<0.05$ was regarded as statistically significant.

\section{Acknowledgments}

This work is supported in part by grants from the Ministry of Education, Science and Culture, Japan, and the Japan Society for the Promotion of Science (grant 21590532), the Takeda Science Foun- dation, the Ichiro Kanehara Memorial Foundation for Medical Research, the Astellas Foundation for Research on Metabolic Disorders, the Yakult Bioscience Foundation, the Sumitomo Foundation, and the Uehara Memorial Foundation (to T. Watanabe).

Received for publication April 8, 2009, and accepted in revised form February 3, 2010.

Address correspondence to: Warren Strober, Mucosal Immunity Section, Laboratory of Host Defenses, National Institute of Allergy and Infectious Diseases, NIH, Building 10-CRC, Room 5W3940, 10 Center Drive, Bethesda, Maryland 20892, USA. Phone: 301.496.6810; Fax: 301.402.2240; E-mail: wstrober@niaid.nih.gov. Or to: Tomohiro Watanabe, Department of Gastroenterology and Hepatology, Kyoto University Graduate School of Medicine, 54 Shogoin Kawahara-cho, Sakyo-ku, Kyoto 606-8507, Japan. Phone: 81.75.751.4319; Fax: 81.75.751.4303; E-mail: tmhrwtnb@kuhp.kyoto-u.ac.jp.
1. Strober W, Murray PJ, Kitani A, Watanabe T. Signalling pathways and molecular interactions of NOD1 and NOD2. Nat Rev Immunol. 2006;6(1):9-20.

2. Watanabe T, Kitani A, Strober W. NOD2 regulation of Toll-like receptor responses and the pathogenesis of Crohn's disease. Gut. 2005;54(11):1515-1518.

3. Chen G, Shaw MH, Kim YG, Nunez G. Nod-like receptors: role in innate immunity and inflammatory disease. Annu Rev Pathol. 2009;4:365-398.

4. Inohara N, Nunez G. NODs: intracellular proteins involved in inflammation and apoptosis. Nat Rev Immunol. 2003;3(5):371-382.

5. Inohara N, Chamaillard M, McDonald C, Nunez G. NOD-LRR proteins: role in host-microbial interactions and inflammatory disease. Annu Rev Biochem. 2005;74:355-383.

6. Hisamatsu T, Suzuki M, Podolsky DK. Interferon-gamma augments CARD4/NOD1 gene and protein expression through interferon regulatory factor-1 in intestinal epithelial cells. J Biol Chem. 2003;278(35):32962-32968.

7. Kim JG, Lee SJ, Kagnoff MF. Nod1 is an essential signal transducer in intestinal epithelial cells infected with bacteria that avoid recognition by toll-like receptors. Infect Immun. 2004;72 (3):1487-1495.

8. Ogura Y, et al. Expression of NOD2 in Paneth cells: a possible link to Crohn's ileitis. Gut. 2003; 52(11):1591-1597.

9. Masumoto J, et al. Nod1 acts as an intracellular receptor to stimulate chemokine production and neutrophil recruitment in vivo. J Exp Med. 2006; 203(1):203-213.

10. Chamaillard M, et al. An essential role for NOD1 in host recognition of bacterial peptidoglycan containing diaminopimelic acid. Nat Immunol. 2003;4(7):702-707.

11. Inohara $\mathrm{N}$, et al. An induced proximity model for NF-kappa B activation in the Nod1/RICK and RIP signaling pathways. J Biol Chem. 2000; 275(36):27823-27831.

12. Viala J, et al. Nod1 responds to peptidoglycan delivered by the Helicobacter pylori cag pathogenicity island. Nat Immunol. 2004;5(11):1166-1174.

13. Watanabe T, Kitani A, Murray PJ, Strober W. NOD2 is a negative regulator of Toll-like receptor 2-mediated T helper type 1 responses. Nat Immunol. 2004; 5(8):800-808.

14. Yang Y, Yin C, Pandey A, Abbott D, Sassetti C, Kelliher MA. NOD2 pathway activation by MDP or Mycobacterium tuberculosis infection involves the stable polyubiquitination of Rip2. J Biol Chem. 2007; 282(50):36223-36229.

15. Girardin SE, et al. CARD4/Nod1 mediates NFkappaB and JNK activation by invasive Shigella flexneri. EMBO Rep. 2001;2(8):736-742.
16. da Silva Correia J, Miranda Y, Leonard N, Ulevitch R. SGT1 is essential for Nod1 activation. Proc Natl Acad Sci U S A. 2007;104(16):6764-6769.

17. da Silva Correia J, Miranda Y, Leonard N, Hsu J, Ulevitch RJ. Regulation of Nod1-mediated signaling pathways. Cell Death Differ. 2007;14(4):830-839.

18. Argast GM, Fausto N, Campbell JS. Inhibition of RIP2/RIck/CARDIAK activity by pyridinyl imidazole inhibitors of p38 MAPK. Mol Cell Biochem. 2005; 268(1-2):129-140.

19. Saito N, et al. Two carboxyl-terminal activation regions of Epstein-Barr virus latent membrane protein 1 activate NF-kappaB through distinct signaling pathways in fibroblast cell lines. J Biol Chem. 2003; 278(47):46565-46575.

20. Oganesyan G, et al. Critical role of TRAF3 in the Toll-like receptor-dependent and -independent antiviral response. Nature. 2006;439(7073):208-211.

21. Hacker $H$, et al. Specificity in Toll-like receptor signalling through distinct effector functions of TRAF3 and TRAF6. Nature. 2006;439(7073):204-207.

22. Ishii KJ, et al. A Toll-like receptor-independent antiviral response induced by double-stranded B-form DNA. Nat Immunol. 2006;7(1):40-48.

23. Zarnegar B, Yamazaki S, He JQ, Cheng G. Control of canonical NF-kappaB activation through the NIK-IKK complex pathway. Proc Natl Acad SciUS A. 2008;105(9):3503-3508.

24. Marx N, et al. Peroxisome proliferator-activated receptor-gamma activators inhibit IFN-gammainduced expression of the T cell-active CXC chemokines IP-10, Mig, and I-TAC in human endothelial cells. J Immunol. 2000;164(12):6503-6508.

25. Majumder S, Zhou LZ, Chaturvedi P, Babcock G, Aras S, Ransohoff RM. p48/STAT-1alpha-containing complexes play a predominant role in induction of IFN-gamma-inducible protein, $10 \mathrm{kDa}$ (IP-10) by IFN-gamma alone or in synergy with TNF-alpha. J Immunol. 1998;161(9):4736-4744.

26. Taniguchi T, Takaoka A. A weak signal for strong responses: interferon-alpha/beta revisited. Nat Rev Mol Cell Biol. 2001;2(5):378-386.

27. Taniguchi $\mathrm{T}$, Takaoka A. The interferon-alpha/ beta system in antiviral responses: a multimodal machinery of gene regulation by the IRF family of transcription factors. Curr Opin Immunol. 2002; 14(1):111-116.

28. Shin-Ya M, et al. Intracellular interferon triggers Jak/Stat signaling cascade and induces p53-dependent antiviral protection. Biochem Biophys Res Commun. 2005;329(3):1139-1146.

29. Yoshida M, et al. Differential localization of colitogenic Th 1 and Th 2 cells monospecific to a microflora-associated antigen in mice. Gastroenterology. 2002; 123(6):1949-1961.
30. Muller U, et al. Functional role of type I and type II interferons in antiviral defense. Science. 1994; 264(5167):1918-1921.

31. Matsumoto Y, et al. Helicobacter pylori infection triggers aberrant expression of activation-induced cytidine deaminase in gastric epithelium. Nat Med. 2007; 13(4):470-476.

32. Hirata Y, et al. MyD88 and TNF receptor-associated factor 6 are critical signal transducers in Helicobacter pylori-infected human epithelial cells. J Immunol. 2006;176(6):3796-3803.

33. Fritz JH, et al. Nod1-mediated innate immune recognition of peptidoglycan contributes to the onset of adaptive immunity. Immunity. 2007;26(4):445-459.

34. Okabe M, Ikawa M, Kominami K, Nakanishi T, Nishimune Y. 'Green mice' as a source of ubiquitous green cells. FEBS Lett. 1997;407(3):313-319.

35. Watanabe T, et al. Muramyl dipeptide activation of nucleotide-binding oligomerization domain 2 protects mice from experimental colitis. J Clin Invest. 2008;118(2):545-559.

36. Fichtner-Feigl S, Fuss IJ, Preiss JC, Strober W, Kitani A. Treatment of murine Th1- and Th2-mediated inflammatory bowel disease with NF-kappa B decoy oligonucleotides. J Clin Invest. 2005;115(11):3057-3071.

37. Kobayashi K, et al. RICK/Rip2/CARDIAK mediates signalling for receptors of the innate and adaptive immune systems. Nature. 2002;416(6877):194-199.

38. McCarthy JV, Ni J, Dixit VM. RIP2 is a novel NFkappaB-activating and cell death-inducing kinase. J Biol Chem. 1998;273(27):16968-16975.

39. Veckman V, Osterlund P, Fagerlund R, Melen K, Matikainen S, Julkunen I. TNF-alpha and IFNalpha enhance influenza-A-virus-induced chemokine gene expression in human A549 lung epithelial cells. Virology. 2006;345(1):96-104.

40. Katakura K, Lee J, Rachmilewitz D, Li G, Eckmann L, Raz E. Toll-like receptor 9-induced type I IFN protects mice from experimental colitis. JClin Invest. 2005;115(3):695-702.

41. Thomas KE, Galligan CL, Newman RD, Fish EN, Vogel SN. Contribution of interferon-beta to the murine macrophage response to the toll-like receptor 4 agonist, lipopolysaccharide. J Biol Chem. 2006; 281(41):31119-31130.

42. Park JH, et al. Nod1/RICK and TLR signaling regulate chemokine and antimicrobial innate immune responses in mesothelial cells. J Immunol. 2007; 179(1):514-521.

43. Fukazawa A, et al. GEF-H1 mediated control of NOD1 dependent NF-kappaB activation by Shigella effectors. PLoS Pathog. 2008;4(11):e1000228.

44. Decker T, Muller M, Stockinger S. The yin and yang of type I interferon activity in bacterial infection. Nat Rev Immunol. 2005;5(9):675-687. 
45. Uemura N, et al. Helicobacter pylori infection and the development of gastric cancer. $N$ Engl J Med. 2001;345(11):784-789.

46. D'Elios MM, et al. T helper 1 effector cells specific for Helicobacter pylori in the gastric antrum of patients with peptic ulcer disease. J Immunol. 1997;158(2):962-967.

47. Itoh $\mathrm{T}$, et al. The vast majority of gastric $\mathrm{T}$ cells are polarized to produce $\mathrm{T}$ helper 1 type cytokines upon antigenic stimulation despite the absence of Helicobacter pylori infection. J Gastroenterol. 1999; 34(5):560-570

48. Garhart CA, Nedrud JG, Heinzel FP, Sigmund NE, Czinn SJ. Vaccine-induced protection against Helicobacter pylori in mice lacking both antibodies and interleukin-4. Infect Immun. 2003;71(6):3628-3633.

49. Andersen-Nissen E, et al. Evasion of Toll-like receptor 5 by flagellated bacteria. Proc Natl Acad SciUS A. 2005; 102(26):9247-9252.

50. Ferrero RL. Innate immune recognition of the extracellular mucosal pathogen, Helicobacter pylori. Mol Immunol. 2005;42(8):879-885.

51. Amedei A, et al. The neutrophil-activating protein of Helicobacter pylori promotes Th1 immune responses. J Clin Invest. 2006;116(4):1092-1101.

52. Christen U, Von Herrath MG. IP-10 and type 1 diabetes: a question of time and location. Autoimmunity. 2004;37(5):273-282.

53. Eck M, et al. CXC chemokines Gro(alpha)/IL-8 and IP-10/MIG in Helicobacter pylori gastritis. Clin Exp Immunol. 2000;122(2):192-199.

54. Gautier $\mathrm{G}$, et al. A type I interferon autocrine-paracrine loop is involved in Toll-like receptor-induced interleukin-12p70 secretion by dendritic cells. J Exp Med. 2005;201(9):1435-1446.

55. Opitz B, et al. Nod1-mediated endothelial cell activation by Chlamydophila pneumoniae. Circ Res. 2005; 96(3):319-326.

56. Travassos LH, et al. Nod1 participates in the innate immune response to Pseudomonas aeruginosa.
J Biol Chem. 2005;280(44):36714-36718.

57. Yamamoto M, Fujihashi K, Kawabata K, McGhee JR, Kiyono H. A mucosal intranet: intestinal epithelial cells down-regulate intraepithelial, but not peripheral, T lymphocytes. J Immunol. 1998;160(5):2188-2196.

58. Fujihashi K, et al. Interleukin 2 (IL-2) and interleukin 7 (IL-7) reciprocally induce IL-7 and IL-2 receptors on gamma delta $\mathrm{T}$-cell receptor-positive intraepithelial lymphocytes. Proc Natl Acad SciU S A. 1996;93(8):3613-3618.

59. Dupuis S, et al. Impaired response to interferonalpha/beta and lethal viral disease in human STAT1 deficiency. Nat Genet. 2003;33(3):388-391.

60 . Shirai $Y$, et al. Induction and maintenance of immune effector cells in the gastric tissue of mice orally immunized to Helicobacter pylori requires salivary glands. Gastroenterology. 2000;118(4):749-759.

61. Lovett-Racke AE, et al. Silencing T-bet defines a critical role in the differentiation of autoreactive $T$ lymphocytes. Immunity. 2004;21(5):719-731. 